\title{
Investigating a Hierarchy of Eulerian Closure Models for Scalar Transfer Inside Forested Canopies
}

\author{
Jehn-Yih Juang • Gabriel G. Katul • \\ Mario B. Siqueira • Paul C. Stoy • \\ Heather R. McCarthy
}

Received: 21 February 2007 / Accepted: 27 March 2008 / Published online: 25 April 2008

(C) Springer Science+Business Media B.V. 2008

\begin{abstract}
Modelling the transfer of heat, water vapour, and $\mathrm{CO}_{2}$ between the biosphere and the atmosphere is made difficult by the complex two-way interaction between leaves and their immediate microclimate. When simulating scalar sources and sinks inside canopies on seasonal, inter-annual, or forest development time scales, the so-called well-mixed assumption (WMA) of mean concentration (i.e. vertically constant inside the canopy but dynamically evolving in time) is often employed. The WMA eliminates the need to model how vegetation alters its immediate microclimate, which necessitates formulations that utilize turbulent transport theories. Here, two inter-related questions pertinent to the WMA for modelling scalar sources, sinks, and fluxes at seasonal to inter-annual time scales are explored: (1) if the WMA is to be replaced so as to resolve this two-way interaction, how detailed must the turbulent transport model be? And (2) what are the added predictive skills gained by resolving the two-way interaction vis-à-vis other uncertainties such as seasonal variations in physiological parameters. These two questions are addressed by simulating multi-year mean
\end{abstract}

J.-Y. Juang · G. G. Katul · M. B. Siqueira · P. C. Stoy · H. R. McCarthy

Nicholas School of the Environment and Earth Sciences, Duke University, Durham, NC, USA

J.-Y. Juang $(\varangle)$

Department of Geography, National Taiwan University, No. 1, Sec. 4, Roosevelt Road, Taipei 10617 ,

Taiwan

e-mail: jjuang@ntu.edu.tw

G. G. Katul

Department of Civil and Environmental Engineering, Duke University, Durham, NC, USA

Present Address:

M. B. Siqueira

Departamento de Engenharia Mecânica, Universidade de Brasília, Brasilia, Brazil

Present Address:

P. C. Stoy

School of GeoSciences, Department of Atmospheric and Environmental Science, University of Edinburgh, Edinburgh, UK

Present Address:

H. R. McCarthy

Department of Earth System Science, University of California at Irvine, Irvine, CA, USA 
scalar concentration and eddy-covariance scalar flux measurements collected in a Loblolly pine ( $P$. taeda L.) plantation near Durham, North Carolina, U.S.A. using turbulent transport models ranging from K-theory (or first-order closure) to third-order closure schemes. The multi-layer model calculations with these closure schemes were contrasted with model calculations employing the WMA. These comparisons suggested that (i) among the three scalars, sensible heat flux predictions are most biased with respect to eddy-covariance measurements when using the WMA, (ii) first-order closure schemes are sufficient to reproduce the seasonal to inter-annual variations in scalar fluxes provided the canonical length scale of turbulence is properly specified, (iii) second-order closure models best agree with measured mean scalar concentration (and temperature) profiles inside the canopy as well as scalar fluxes above the canopy, (iv) there are no clear gains in predictive skills when using third-order closure schemes over their second-order closure counterparts. At inter-annual time scales, biases in modelled scalar fluxes incurred by using the WMA exceed those incurred when correcting for the seasonal amplitude in the maximum carboxylation capacity $\left(V_{\mathrm{cmax}, 25}\right)$ provided its mean value is unbiased. The role of local thermal stratification inside the canopy and possible computational simplifications in decoupling scalar transfer from the generation of the flow statistics are also discussed.

Keywords Canopy turbulence Closure models · Net ecosystem $\mathrm{CO}_{2}$ exchange · Scalar transfer $\cdot$ Stratified canopy flows

"The tree, tilting its leaves to capture bullets of light; inhaling, exhaling; its many thousand stomata breathing, creating the air". Ruth Stone, 2002, In the Next Galaxy

\section{Introduction}

Quantifying the exchange of scalars (e.g., carbon dioxide $\mathrm{CO}_{2}$, water vapour $\mathrm{H}_{2} \mathrm{O}$, temperature, or other chemical species) between leaves and their local environment (hereafter referred to as microenvironment) is made difficult by a two-way interaction in which the microenvironment exerts controls over scalar exchange at the leaf surface, and leaves have some capacity to regulate their own microenvironment through stomatal opening and closure. This two-way interaction is further complicated by the vertical distribution of foliage within the canopy, leading to significant vertical gradients in the radiation environment and airflow regimes. The intrinsic non-linearity in leaf physiological responses (e.g. leaf-level photosynthesis and transpiration) to radiation further exasperates this difficulty.

To date, most eco-physiological approaches to modelling annual and inter-annual ecosystem-scale carbon and water fluxes have focused on radiative transfer and the nonlinearity in the physiological response to incident radiation at the leaf surface (Aber et al. 1996; De Pury and Farquhar 1997; Kirschbaum et al. 1998; Leuning et al. 1995; Luo et al. 2001; Naumburg et al. 2001; Nikolov et al. 1995; Wang and Leuning 1998; Williams et al. 1996, 1998). These models did not specifically resolve the vertical distribution of the scalar concentration $\left(\mathrm{CO}_{2}\right.$ and $\left.\mathrm{H}_{2} \mathrm{O}\right)$ and temperature, and assume that within the canopy volume, mean scalar concentration is constant and identical to its state above the canopy (hereafter, referred to as the well-mixed assumption, WMA). However, the time evolution of the mean scalar concentrations (and temperature) is generally included given the availability of such measurements above the canopy. The basic premise behind the WMA is that 
temporal variation of the mean scalar concentration (e.g. diurnally or seasonally) far exceeds their vertical variation inside the canopy. Besides, resolving such two-way interaction adds significant computational burden and model complexity because of the need to compute the flow field with perhaps modest gains in predictive skills, though the degree of improvement in resolving sources, sinks, and fluxes remains largely unexplored. Furthermore, uncertainties in describing the non-stationarity and vertical inhomogeneity in physiological parameters (e.g. in photosynthesis calculations) may overshadow any improvements gained by resolving this two-way interaction.

While the WMA may be defensible for some canopy types, it is too simplistic for tallforested ecosystems, especially when such an assumption is confronted with experimental evidence that vertical variations in excess of $50 \mathrm{ppm}$ for $\mathrm{CO}_{2}$ concentration and $3 \mathrm{~K}$ or more for air temperature occur inside the canopy volume even during daytime conditions (Lai et al. 2002b; Siqueira and Katul 2002). Because the vertical variations in mean scalar concentration profiles are not random within the canopy, the WMA may inject systematic biases in modelling scalar sources, sinks, and fluxes. Hence, future developments in ecosystem carbon-water source-sink, and flux modelling are likely to benefit from answering two inter-related questions:

(1) If the WMA in mean scalar concentration is to be revised, then how detailed must the turbulent transport model be to resolve the two-way interaction between the canopy and its microclimate?

(2) When incorporating a detailed turbulent transport model, are the improvements in the overall prediction of scalar sources, sinks, and fluxes sufficiently large when compared to improvements gained by resolving the seasonality in physiological parameters such as the ones most pertinent to leaf photosynthesis? The variability in physiological parameters is rarely included in biogeochemical cycle models.

These two questions frame the study objectives here and are explored using the multi-year record available at the AmeriFlux Duke Forest loblolly pine site as a case study.

Several multi-layer one-dimensional models have been developed to resolve the two-way interaction between leaf and microclimate using turbulent transport theories in conjunction with detailed physiological and radiative transfer principles (Baldocchi 1992; Baldocchi et al. 1997; Baldocchi and Meyers 1998; Leuning et al. 1995; Meyers and Paw 1986, 1987; Raupach 1988, 1989; Simon et al. 2005a,b). The term 'CANVEG' (for 'canopy vegetation') was coined for such multi-layer models that employ time and planar-averaged equations (Baldocchi 1992; Baldocchi et al. 1997; Baldocchi and Meyers 1998). CANVEG models do not resolve explicitly rapid transient physiological responses occurring on turbulent time scales (Gu et al. 1999; Su et al. 1996) or sun-fleck events (Naumburg et al. 2001). The net effect of these phenomena on half-hourly time scales may be parameterized (e.g. by lags or stochastic jumps) but are not considered here. In the original CANVEG (e.g. Baldocchi 1992), linkages between scalar sources and mean concentration relied on the principles of Lagrangian fluid mechanics for characterizing turbulent dispersion (Raupach 1989), which was a major theoretical improvement over classical Eulerian first-order flux-gradient closure models (or K-theory). However, the Lagrangian framework in CANVEG suffered from two fundamental limitations: (i) it cannot explicitly treat thermal stratification inside the canopy volume, known to be significant in tall-forested ecosystems (Malhi et al. 1998; Siqueira and Katul 2002), and (ii) it requires detailed higher-order velocity statistics profiles (e.g., the vertical velocity standard deviation profile), which either have to be measured or simulated. To circumvent these limitations, Lai et al. (2000a,b) and Siqueira et al. (2002) modified the CANVEG approach in Baldocchi (1992) and Baldocchi and Meyers (1998) by employing a 
Eulerian-Lagrangian hybrid framework for turbulent dispersion. The basic premise is to utilize higher order Eulerian closure approaches (Meyers and Paw 1986; Wilson 1989; Wilson and Shaw 1977) to compute the velocity statistics within the canopy, and then use Lagrangian transport theory to couple scalar sources to their mean concentration, while retaining similar physiological and radiative transfer schemes as in CANVEG. The approach in Lai et al. (2002a,b) eliminates one of the two limitations earlier mentioned, but thermal stratification inside the canopy was treated as a modifier to the upper boundary conditions of the modelled velocity statistics and on the Lagrangian integral time scale, an approach also employed by Leuning (2000).

Here, a multilayer biosphere-atmosphere model is developed that retains the detailed eco-physiological parameterization and radiative transfer principles in CANVEG, but the complexity in the turbulent transport scheme needed to capture this two-way interaction between the canopy and its microclimate is varied in a hierarchical manner. Different closure approximations ranging from first-order to third-order schemes are employed to parameterize higher order turbulent moments in the governing conservation equations for both momentum and scalar transfer. As a reference, these model calculations are contrasted with scalar sources (and subsequently fluxes) calculated by the WMA (i.e. a zeroth order closure in the model hierarchy). In addition, these model calculations are repeated with and without resolving the effects of atmospheric stability inside the canopy. Resolving atmospheric stability locally inside the canopy necessitates a computationally demanding iterative scheme for solving simultaneously the Reynolds stress budget and heat flux budget equations, which may not be feasible for inter-annual water and carbon flux calculations.

Because the interest here is in 'ecological' (i.e. seasonal to inter-annual) time scales, closure models with increasing closure complexity are compared against a multi-year record of eddy-covariance sensible and latent heat fluxes and $\mathrm{CO}_{2}$ flux collected in a uniform Loblolly pine (Pinus taeda L.) stand in the Blackwood Division of Duke Forest, described next. Because the CANVEG model does not explicitly account for soil moisture stress (i.e. soilplant hydrodynamics are not considered), the data-model intercomparison is restricted to years with well-watered soil moisture states.

\section{Experiment}

\subsection{Study Site}

All observations were made at a pine stand in the Blackwood Division of the Duke Forest near Durham, North Carolina, U.S.A. (site location: $35^{\circ} 58^{\prime} \mathrm{N}, 79^{\circ} 05^{\prime} \mathrm{W}, 163 \mathrm{~m}$ above sea level) as part of a long-term $\mathrm{H}_{2} \mathrm{O} / \mathrm{CO}_{2}$ flux monitoring initiative (Baldocchi et al. 2001). The study site is a uniformly planted Loblolly pine forest (planted in 1983 at $2 \mathrm{~m} \times 2.4 \mathrm{~m}$ spacing) extending some $300-600 \mathrm{~m}$ in the east-west direction and $1,000 \mathrm{~m}$ in the south-north direction. The long-term mean annual precipitation is $1,185 \pm 177 \mathrm{~mm}$, and the annual mean air temperature is $14.9 \pm 0.9^{\circ} \mathrm{C}$. The local topographic variations around the micrometeorological tower are small enough (slope $<5 \%$ ) to ignore the effect of complex terrain on the flow statistics (Siqueira et al. 2002). In addition to the dominant pine overstorey, the sub-canopy (roughly ranging in height from 0 to $0.4 h$, where $h$ is the mean height of the main canopy) contains some 40 woody species, of which Liquidambar styraciflua L., Acer rubrum L., Ulmus alata Michx., and Cornus florida L. are the most prevalent (Palmroth et al. 2005). 

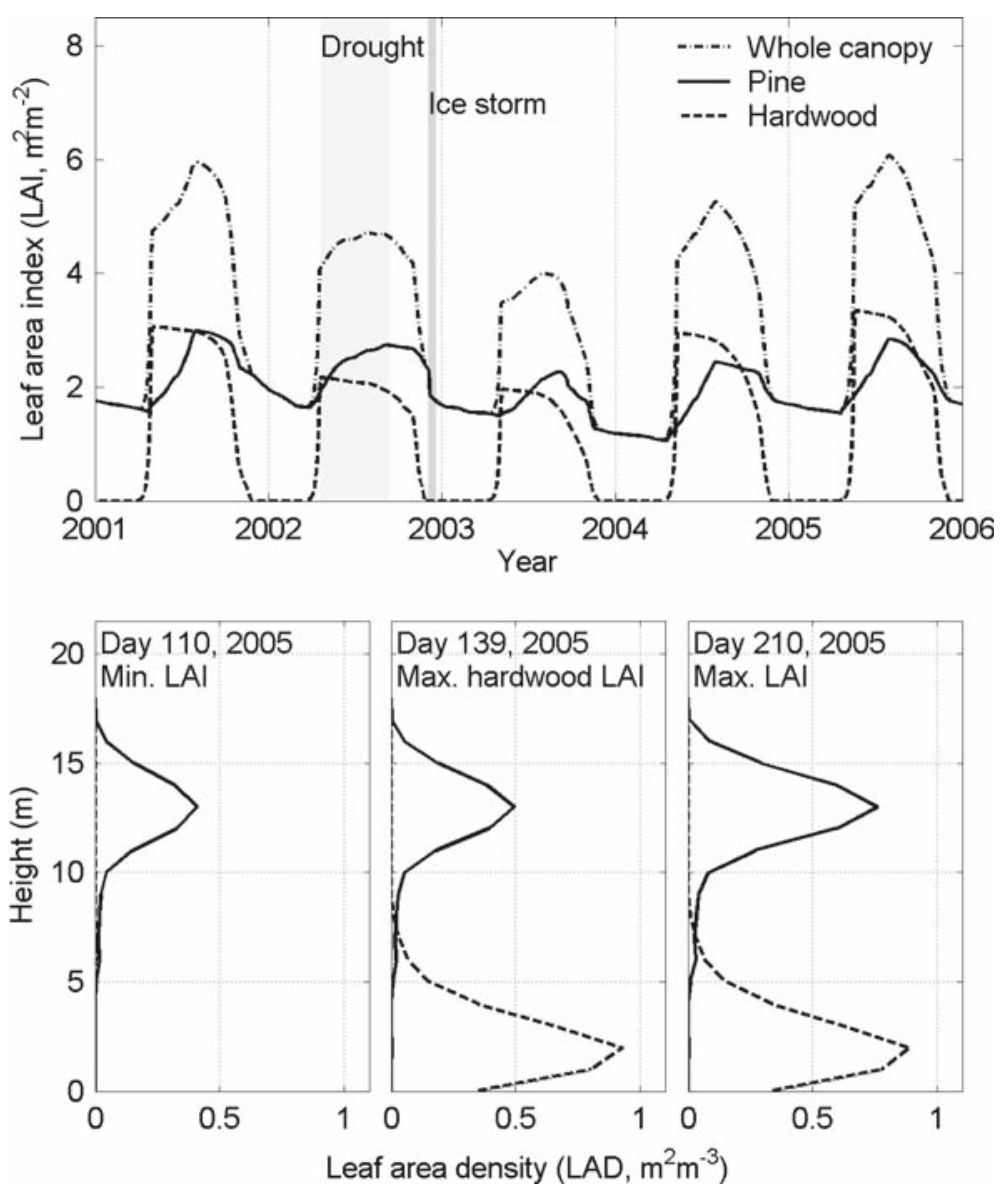

Fig. 1 Top: Leaf area index (LAI, $\mathrm{m}^{2} \mathrm{~m}^{-2}$ ) variation from 2001 to 2005 for the pine canopy and the hardwood understorey. The light grey area and the darker grey area respectively, represent the severe drought event during the growing season and the ice storm event in December 2002. Bottom: the leaf area density (LAD, $\mathrm{m}^{2} \mathrm{~m}^{-3}$ ) profiles at different times of the year based on different LAI values in 2005

While the forest is evergreen, leaf area index (LAI) variations can be significant, as evidenced by the measurements in Fig. 1 (taken from a model-data analysis described by McCarthy et al. (2007) in which multiple data sources were used). During the growing season in 2002, the ecosystem experienced a severe drought lasting several months, and on December 4 and 5 2002, an ice storm occurred causing severe damage to the canopy structure (McCarthy et al. 2006b). The lower panel of Fig. 1 shows the vertical distribution of the foliage at different times of the year. These complex spatial and temporal variations in foliage distribution will have appreciable effects on both the radiation/energy environment and the attenuation of turbulent flow statistics inside the canopy volume, thereby significantly influencing the two-way interaction.

\subsection{Measurements}

The velocity statistics (wind velocity and Reynolds stresses), sensible heat flux $\left(H_{S}\right)$, latent heat flux $\left(L_{v} E\right.$, where $L_{v}$ is the latent heat of vaporization $\left.\left(\mathrm{J} \mathrm{kg}^{-1} \mathrm{~K}^{-1}\right)\right)$, and $\mathrm{CO}_{2}$ fluxes 
were measured at $22.5 \mathrm{~m}$ using an eddy-covariance (hereafter referred to as EC) system composed of a LI-7500 open-path $\mathrm{CO}_{2} / \mathrm{H}_{2} \mathrm{O}$ gas analyzer (Li-Cor Inc., Lincoln, NE, USA) and a CSAT3 tri-axial sonic anemometer (Campbell Scientific Inc., Logan, UT, USA). The EC data were sampled at $10 \mathrm{~Hz}$ and averaged every $30 \mathrm{~min}$. The effects of air density fluctuations on $\mathrm{CO}_{2}$ and $\mathrm{H}_{2} \mathrm{O}$ flux measurements were corrected after Webb et al. (1980), while corrections to scalar statistics beyond the vertical turbulent fluxes are discussed elsewhere (Detto and Katul 2007).

The net radiation $\left(R_{n}\right)$ was measured using a Fritschen-type net radiometer at the tower top (at $24 \mathrm{~m}$ ) from 1997 until 2003, and then this radiometer was replaced with a Kipp \& Zonen CNR1 net radiometer (Kipp \& Zonen USA Inc., Bohemia, NY, USA) in 2004. The photosynthetically active radiation (PAR) was measured with a Li-Cor LI-190SA quantum sensor at the canopy top, and mean air temperature and relative humidity were measured using a Campbell Scientific HMP35C temperature/relative humidity probe at (2/3)h. To sample the vertical distribution of scalar concentrations, a multi-port system was installed at 10 different levels $(0.1,0.75,1.5,3.5,5.5,7.5,9.5,11.5,13.5$, and $15.5 \mathrm{~m})$ and a $\mathrm{Li}-\mathrm{Cor} 6262 \mathrm{CO}_{2} / \mathrm{H}_{2} \mathrm{O}$ infrared gas analyzer was used to measure the mean concentrations. Another profiling system was employed to measure the mean air temperature at eight levels $(1.5,3.5,5.5,7.5,9.5$, $11.5,13.5$, and $15.5 \mathrm{~m}$ ) using shielded copper-constantan thermocouple sensors.

The forest floor $\mathrm{CO}_{2}$ efflux was measured with an automated carbon efflux system (ACES, US Patent 6692970) developed by the USDA Forest Service, Southern Research Station Laboratory in Research Triangle Park, NC (Butnor et al. 2003; Butnor and Johnsen 2004; Palmroth et al. 2005), whose configuration details, quality checks, and spatial sampling area are described in Palmroth et al. (2005). These measurements were used to drive the lower boundary conditions for the mean $\mathrm{CO}_{2}$ continuity equation (see Appendix A).

The plant area index (PAI, $\mathrm{m}^{2} \mathrm{~m}^{-2}$ ) was measured several times per year using a pair of Li-Cor LAI 2000 optical sensors. The plant area density (hereafter PAD, $\mathrm{m}^{2} \mathrm{~m}^{-3}$ ) measurements were conducted at 1-m intervals from the forest floor up to the canopy top (Lai et al. 2000a; Pataki et al. 1998; Schafer et al. 2003). The dynamics of leaf area were reconstructed for broadleaf species, using data on leaf litterfall mass and timing, specific leaf area and allometry, and for Pinus taeda, needle litterfall (lagged by 2 years to account for foliage longevity) and timing, combined with needle elongation rates, and fascicle and shoot counts (McCarthy et al. 2006a). Further details about the site and data processing are described elsewhere (Juang et al. 2006; Oren et al. 1998; Palmroth et al. 2005; Pataki and Oren 2003; Stoy et al. 2005).

\section{Theory}

\subsection{Governing Equation}

For completeness, the models employed in the turbulent closure hierarchy are briefly reviewed. For a steady-state, incompressible, high Reynolds number and Peclet number flow, the timeand spatially-averaged budget equation for the mean longitudinal momentum, in the absence of Coriolis effects and for the case of a planar-homogeneous canopy, can be expressed as (Katul and Albertson 1998; Meyers and Paw 1987; Wilson and Shaw 1977)

$$
\frac{\partial\langle\bar{u}\rangle}{\partial t}=0=-C_{\mathrm{d}} A(z)\langle\bar{u}\rangle^{2}-\frac{\partial\left\langle\overline{u^{\prime} w^{\prime}}\right\rangle}{\partial z},
$$


where $u$ and $w$ are the instantaneous longitudinal and vertical velocity components, $C_{\mathrm{d}}$ is the drag coefficient (Wilson and Shaw 1977), and $A(z)$ is the bulk PAD at level z. Overbars and brackets represent temporal and spatial averaging of a flow variable, and primed quantities denote departures from this average. Using multiple sonic anemometer measurements, Katul and Albertson (1998) determined $C_{\mathrm{d}}=0.2$ for this stand, a value used throughout our study.

Using similar simplifications and averaging procedures, the steady state budget equation for an arbitrary scalar $\xi$ is given by

$$
\frac{\partial\langle\bar{\xi}\rangle}{\partial t}=0=S_{\xi}-\frac{\partial\left\langle\overline{w^{\prime} \xi^{\prime}}\right\rangle}{\partial z},
$$

where $S_{\xi}$ are local sources and sinks related to the vegetation elements.

Assuming Fickian diffusion (or its resistor analogy) for mass transfer from the leaf to the surrounding atmosphere, the difference in scalar quantities between the leaves and the surrounding air becomes the driver for $S_{\xi}$. Upon scaling with the local leaf area density (LAD), $a(z)$, leads to a spatially-averaged source given by

$$
S_{\zeta}=a(z) G_{\zeta}\left(\left|\overline{\xi_{\mathrm{L}}}\right\rangle-\langle\bar{\xi}\rangle\right)
$$

where $G_{\zeta}\left(\mathrm{m} \mathrm{s}^{-1}\right)$ is the bulk conductance for scalar $\xi$ between the leaves and the surrounding air, and $\xi_{L}$ is the mean quantity of a specific scalar $(\xi)$ inside the leaf, which may be one of the three considered here: the leaf surface temperature (at the skin) $\left\langle\overline{T_{\mathrm{L}}}\right\rangle$, the intercellular saturated water vapour concentration $\left\langle\overline{q_{\mathrm{L}}}\right\rangle$, and the intercellular $\mathrm{CO}_{2}$ concentration $\left\langle\overline{C_{\mathrm{L}}}\right.$. For water vapour and $\mathrm{CO}_{2}$ concentrations, $G_{\zeta}$ includes both stomatal conductance $\left(g_{\mathrm{s}, \xi}\right.$, mol m$\left.{ }^{-2} \mathrm{~s}^{-1}\right)$ and boundary-layer conductance $\left(g_{\mathrm{b}, \xi}, \mathrm{mol} \mathrm{m}^{-2} \mathrm{~s}^{-1}\right)$, while only boundarylayer conductance contributes to heat transfer. Note that PAD is responsible for momentum extraction and light interception, but only LAD is responsible for the simultaneous water vapour release and $\mathrm{CO}_{2}$ uptake by the leaves, though the two quantities are considered to be approximately the same for this evergreen stand.

Using a flat-plate boundary-layer analogy at the leaf surface, the boundary-layer conductance is given by (Campbell and Norman 1998):

$$
g_{\mathrm{b}, \xi}=v_{\xi}\left(\frac{\langle\bar{u}\rangle}{0.7 d}\right)^{0.5}
$$

where $v_{\xi}$ is a molecular transfer coefficient for scalar $\xi$, and $d$ is the characteristic length of the leaf. Here, $d=0.0015 \mathrm{~m}$ for the pine foliage and $d=0.15 \mathrm{~m}$ for the understorey broadleaf foliage.

\subsection{Closure Approximation}

In Eqs. 1 and 2, the turbulent momentum $\left\langle\overline{u^{\prime} w^{\prime}}\right\rangle$ and scalar $\left\langle\overline{w^{\prime} \xi^{\prime}}\right\rangle$ fluxes are additional unknowns that require parameterization so that sources, sinks, fluxes, and concentration can be solved. In the hierarchy of models, either parameterizations or full budget equations for these higher-order terms are derived. 


\subsubsection{First-order Closure Model}

The first-order closure approximation (or K-theory) simply parameterizes the turbulent fluxes in Eqs. 1 and 2 into

$$
\begin{aligned}
& \left\langle\overline{u^{\prime} w^{\prime}}\right\rangle=-K_{\mathrm{m}} \frac{\partial\langle\bar{u}\rangle}{\partial z}, \\
& \left\langle\overline{w^{\prime} \xi^{\prime}}\right\rangle=-K_{\xi} \frac{\partial\langle\bar{\xi}\rangle}{\partial z},
\end{aligned}
$$

where $K$ is the eddy diffusivity, parameterized based on the Prandtl-von Karman mixing length hypothesis as

$$
K=L(z)^{2}\left|\frac{\partial\langle\bar{u}\rangle}{\partial z}\right|,
$$

where $L(z)$ is a canonical mixing length at height $z$. Katul et al. (2004) recently summarized previous work on specifying time or length scales inside canopies (Liu et al. 1996; Massman and Weil 1999; Poggi et al. 2004) and concluded that $L(z)$ may be assumed approximately constant inside the canopy volume for a dense canopy and can be estimated from:

$$
L(z)= \begin{cases}\alpha_{m l} h ; & z<h \\ k\left(z-d_{0}\right) & z \geq h,\end{cases}
$$

where $k=0.4$ is the von Karman constant, and $d_{0}$ is the zero-plane displacement height determined from the centroid of the drag force (Jackson 1981; Thom 1971). The parameter $\alpha_{m l}$ is calculated by assuming that $L(z)$ is continuous at the canopy top (Katul et al. 2004).

\subsubsection{Second-order Closure Model}

Instead of using K-theory to characterize turbulent fluxes in Eqs. 1 and 2, budget equations can be derived for the turbulent flux though triple correlation terms must be subsequently parameterized. For the momentum and Reynolds stress equations, standard closure approximations result in (Wilson and Shaw 1977; Katul and Albertson 1998; Katul and Chang 1999)

$$
\begin{gathered}
\frac{\partial\left\langle\overline{u^{\prime} w^{\prime}}\right\rangle}{\partial t}=0=-\left\langle\overline{w^{\prime} w^{\prime}}\right\rangle \frac{\partial\langle\bar{u}\rangle}{\partial z}-\frac{Q\left\langle\overline{u^{\prime} w^{\prime}}\right\rangle}{3 \lambda_{2}}+C_{\mathrm{w}} Q^{2} \frac{\partial\langle\bar{u}\rangle}{\partial z}-\frac{\partial}{\partial z}\left\langle\overline{w^{\prime} u^{\prime} w^{\prime}}\right\rangle, \\
\frac{\partial\left\langle\overline{u^{\prime} u^{\prime}}\right\rangle}{\partial t}=0=-2\left(\left\langle\overline{u^{\prime} w^{\prime}}\right\rangle \frac{\partial\langle\bar{u}\rangle}{\partial z}+\langle\bar{u}\rangle \frac{\partial\left\langle\overline{u^{\prime} w^{\prime}}\right\rangle}{\partial z}\right)-\frac{Q}{3 \lambda_{2}}\left(\left\langle\overline{u^{\prime} u^{\prime}}\right\rangle-\frac{Q^{2}}{3}\right) \\
\frac{\partial\left\langle\overline{v^{\prime} v^{\prime}}\right\rangle}{\partial t}=0=-\frac{Q}{3} \frac{Q^{3}}{\lambda_{3}}-\frac{\partial}{\partial z}\left\langle\overline{w^{\prime} u^{\prime} u^{\prime}}\right\rangle, \\
\frac{\partial\left\langle\overline{w^{\prime} w^{\prime}}\right\rangle}{\partial t}=0=-\frac{Q}{3 \lambda_{2}}\left(\left\langle\overline{w^{\prime} w^{\prime}}\right\rangle-\frac{Q^{2}}{3}\right)-\frac{2}{3} \frac{Q^{2}}{\lambda_{3}}+\frac{2 g}{\langle\bar{T}\rangle}\left\langle\overline{w^{\prime} T^{\prime}}\right\rangle-\frac{\partial}{\partial z}\left\langle\overline{w^{\prime} w^{\prime} w^{\prime}}\right\rangle,
\end{gathered}
$$


where $g$ is the gravitational acceleration, $Q$ is the characteristic turbulent velocity given by $\sqrt{\left\langle\overline{\left.u_{i}^{\prime} u_{i}^{\prime}\right\rangle}\right.}$, and $\lambda_{1}, \lambda_{2}$, and $\lambda_{3}$ are the characteristic length scales for the triple velocity correlations, the pressure-velocity gradient correlations, and the viscous dissipation, respectively. These three length scales are determined by $\lambda_{i}=a_{i} \times L$, where $a_{i}$ and $C_{\mathrm{w}}$ are similarity constants.

Similarly, the closure approximation of the turbulent scalar flux for $\xi\left(\left\langle\overline{w^{\prime} \xi^{\prime}}\right\rangle\right)$ can be derived using:

$\frac{\partial\left\langle\overline{w^{\prime} \xi^{\prime}}\right\rangle}{\partial t}=0=-\left\langle\overline{w^{\prime} w^{\prime}}\right\rangle \frac{\partial\langle\xi\rangle}{\partial z}-\frac{Q}{3 \lambda_{2}}\left\langle\overline{w^{\prime} \xi^{\prime}}\right\rangle+\frac{g}{\langle\bar{T}\rangle}\left\langle\overline{T^{\prime} \xi^{\prime}}\right\rangle-2 \frac{Q}{\lambda_{3}}\left\langle\overline{w^{\prime} \xi^{\prime}}\right\rangle+\frac{\partial}{\partial z}\left\langle\overline{w^{\prime} w^{\prime} \xi^{\prime}}\right\rangle$.

Note that the third terms on the right-hand side of equations (8d) and (9) are the buoyant production/consumption that necessitate coupling between momentum and scalar exchange. The steady-state budget equation for the correlation term $\left\langle\overline{T^{\prime} \xi^{\prime}}\right\rangle$ is given as

$$
\frac{\partial\left\langle\overline{T^{\prime} \xi^{\prime}}\right\rangle}{\partial t}=0=-\left\langle\overline{w^{\prime} \xi^{\prime}}\right\rangle \frac{\partial\langle\xi\rangle}{\partial z}-\left\langle\overline{w^{\prime} T^{\prime}}\right\rangle \frac{\partial\langle\xi\rangle}{\partial z}-2 \frac{Q}{\lambda_{3}}\left\langle\overline{T^{\prime} \xi^{\prime}}\right\rangle+\frac{\partial}{\partial z}\left\langle\overline{w^{\prime} T^{\prime} \xi^{\prime}}\right\rangle .
$$

In Eqs. 8-10, the triple correlation terms are extra unknowns that require closure assumptions. The following second-order closure approximation proposed by Mellor (1973) and modified by Wilson and Shaw (1977) is employed to parameterize the turbulent fluxes of the Reynolds stresses in Eq. 8,

$$
\begin{aligned}
& \left\langle\overline{w^{\prime} u^{\prime} w^{\prime}}\right\rangle=-2 Q \lambda_{1} \frac{\partial\left\langle\overline{u^{\prime} w^{\prime}}\right\rangle}{\partial z}, \\
& \left\langle\overline{w^{\prime} u^{\prime} u^{\prime}}\right\rangle=-Q \lambda_{1} \frac{\partial\left\langle\overline{u^{\prime} u^{\prime}}\right\rangle}{\partial z}, \\
& \left\langle\overline{w^{\prime} v^{\prime} v^{\prime}}\right\rangle=-Q \lambda_{1} \frac{\partial\left\langle\overline{v^{\prime} v^{\prime}}\right\rangle}{\partial z}, \\
& \left\langle\overline{w^{\prime} w^{\prime} w^{\prime}}\right\rangle=-3 Q \lambda_{1} \frac{\partial\left\langle\overline{w^{\prime} w^{\prime}}\right\rangle}{\partial z} .
\end{aligned}
$$

Similarly, the turbulent fluxes of the scalars and buoyant terms can be expressed as

$$
\begin{aligned}
& \left\langle\overline{w^{\prime} w^{\prime} \xi^{\prime}}\right\rangle=-2 Q \lambda_{1} \frac{\partial\left\langle\overline{w^{\prime} \xi^{\prime}}\right\rangle}{\partial z}, \\
& \left\langle\overline{w^{\prime} T^{\prime} \xi^{\prime}}\right\rangle=-Q \lambda_{1} \frac{\partial\left\langle\overline{T^{\prime} \xi^{\prime}}\right\rangle}{\partial z} .
\end{aligned}
$$

Details of the closure approximations for Eqs. 8-11 are discussed in Appendix A.

\subsubsection{Third-order Closure Model}

Unlike the second-order closure model, third-order closure schemes do not parameterize the triple correlation terms but employ full budget equations. Here, the equations derived and 
discussed in previous studies (Katul and Albertson 1998; Meyers and Paw 1986, 1987) are used. To contrast with second-order closure modelling (Eq. 11b), their outcome for the triple moments are summarized below (Katul and Albertson 1998; Meyers and Paw 1986, 1987):

$$
\begin{aligned}
\left\langle\overline{w^{\prime} u^{\prime} u^{\prime}}\right\rangle= & -\frac{\tau}{C_{1}}\left(2\left\langle\overline{w^{\prime} u^{\prime} w^{\prime}}\right\rangle \frac{\partial\langle\bar{u}\rangle}{\partial z}+\left\langle\overline{w^{\prime} w^{\prime}}\right\rangle \frac{\partial\left\langle\overline{u^{\prime} u^{\prime}}\right\rangle}{\partial z}+4\left\langle\overline{u^{\prime} w^{\prime}}\right\rangle \frac{\partial\left\langle\overline{u^{\prime} w^{\prime}}\right\rangle}{\partial z}\right), \\
\left\langle\overline{w^{\prime} u^{\prime} w^{\prime}}\right\rangle= & -\frac{\tau}{C_{1}}\left(\left\langle\overline{w^{\prime} w^{\prime} w^{\prime}}\right\rangle \frac{\partial\langle\bar{u}\rangle}{\partial z}+\left\langle\overline{u^{\prime} w^{\prime}}\right\rangle \frac{\partial\left\langle\overline{w^{\prime} w^{\prime}}\right\rangle}{\partial z}+3\left\langle\overline{u^{\prime} w^{\prime}}\right\rangle \frac{\partial\left\langle\overline{u^{\prime} w^{\prime}}\right\rangle}{\partial z}\right) \\
\left\langle\overline{w^{\prime} w^{\prime} w^{\prime}}\right\rangle= & -\frac{\tau}{C_{1}}\left(3\left\langle\overline{w^{\prime} w^{\prime}}\right\rangle \frac{\partial\left\langle\overline{w^{\prime} w^{\prime}}\right\rangle}{\partial z}\right), \\
\left\langle\overline{w^{\prime} v^{\prime} v^{\prime}}\right\rangle= & -\frac{\tau}{C_{1}}\left(\left\langle\overline{w^{\prime} w^{\prime}}\right\rangle \frac{\partial\left\langle\overline{v^{\prime} v^{\prime}}\right\rangle}{\partial z}\right), \\
\left\langle\overline{w^{\prime} w^{\prime} \xi^{\prime}}\right\rangle= & -\frac{\tau}{C_{1}}\left(\left\langle\overline{w^{\prime} w^{\prime} w^{\prime}}\right\rangle \frac{\partial\langle\bar{\xi}\rangle}{\partial z}+\left\langle\overline{w^{\prime} \xi^{\prime}}\right\rangle \frac{\partial\left\langle\overline{w^{\prime} w^{\prime}}\right\rangle}{\partial z}+2\left\langle\overline{w^{\prime} w^{\prime}}\right\rangle \frac{\partial\left\langle\overline{w^{\prime} \xi^{\prime}}\right\rangle}{\partial z}\right), \\
\left\langle\overline{w^{\prime} T^{\prime} \xi^{\prime}}\right\rangle= & -\frac{\tau}{C_{1}}\left(\left\langle\overline{w^{\prime} w^{\prime} \xi^{\prime}}\right\rangle \frac{\partial\langle\bar{T}\rangle}{\partial z}+\left\langle\overline{w^{\prime} w^{\prime} T^{\prime}}\right\rangle \frac{\partial\langle\bar{\xi}\rangle}{\partial z}\right. \\
& \left.+\left\langle\overline{w^{\prime} w^{\prime}}\right\rangle \frac{\partial\left\langle\overline{T^{\prime} \xi^{\prime}}\right\rangle}{\partial z}+\left\langle\overline{w^{\prime} T^{\prime}}\right\rangle \frac{\partial\left\langle\overline{w^{\prime} \xi}\right\rangle}{\partial z}+\left\langle\overline{w^{\prime} \xi}\right\rangle \frac{\partial\left\langle\overline{w^{\prime} T^{\prime}}\right\rangle}{\partial z}\right\rangle
\end{aligned}
$$

In Eq. 12, the coefficient $C_{1}$ is a similarity constant and $\tau$ is a relaxation time scale defined as $Q^{2} / \varepsilon$, where $\varepsilon=\frac{2}{3} \frac{Q^{3}}{\lambda_{3}}$ is the mean turbulent kinetic energy dissipation rate. More details are provided in Appendix A.

\subsection{Radiation Budget within the Canopy Volume}

The radiative distribution within the canopy volume uses a multi-layer light attenuation model described in Leuning et al. (1995) and Schafer et al. (2003). Basic concepts and applications can be found elsewhere (Campbell and Norman 1998; Erbs et al. 1982; Goudriaan and van Laar 1994; Pataki et al. 1998; Spitters et al. 1986; Spitters 1986; Stenberg 1998), but for completeness, salient features of the model are summarised below.

The total incoming solar radiation contains two major components with different spectra: the visible (VIS) and near-infrared radiation (NIR). Because the attenuation properties of VIS and NIR within the canopy are different, the distributions of these two portions are treated separately (Weiss and Norman 1985).

The isothermal form of net radiation $\left(R_{\mathrm{n}}\right)$ absorbed by the leaves at level $z$ is given by (Leuning et al. 1995)

$$
R_{\mathrm{n}}(z)=S_{\mathrm{A}}(z)-R_{\mathrm{L}}(z),
$$


where $S_{\mathrm{A}}$ is the shortwave radiation absorbed by the leaves, and $R_{\mathrm{L}}$ is the isothermal net longwave radiation, discussed in Appendix B.

Within the canopy volume, sunlit leaves absorb all the radiative components, the direct beam $S_{\mathrm{A}, \mathrm{b}}(z)$, diffuse $S_{\mathrm{A}, \mathrm{d}}(z)$, and scattered radiation $S_{\mathrm{A}, \mathrm{s}}(z)$, given by $S_{\mathrm{A}, \mathrm{sl}}(z)=S_{\mathrm{A}, \mathrm{b}}(z)+$ $S_{\mathrm{A}, \mathrm{d}}(z)+S_{\mathrm{A}, \mathrm{s}}(z)$, while shaded leaves only absorb the diffuse and scattered components, i.e. $S_{\mathrm{A}, \mathrm{sh}}(z)=S_{\mathrm{A}, \mathrm{d}}(z)+S_{\mathrm{A}, \mathrm{s}}(z)$ (Campbell and Norman 1998; Leuning et al. 1995; Schafer et al. 2003), where $S_{\mathrm{A}, \mathrm{sl}}(z)$ and $S_{\mathrm{A}, \mathrm{sh}}(z)$ are the absorbed shortwave radiation fluxes on sunlit and shaded leaves, respectively (see Appendix B for a detailed discussion).

The vertical distribution of absorbed shortwave radiation for the sunlit $\left(S_{\mathrm{A}, \mathrm{sl}}\right)$ and shaded leaves $\left(S_{\mathrm{A}, \mathrm{sh}}\right)$ can be calculated as

$$
\begin{aligned}
& S_{\mathrm{A}, \mathrm{sl}}(z)=f_{\mathrm{sl}}(z) S_{\mathrm{A}, \mathrm{sl}, \mathrm{VIS}}(z)+f_{\mathrm{sl}}(z) S_{\mathrm{A}, \mathrm{sl}, \mathrm{NIR}}(z), \\
& S_{\mathrm{A}, \mathrm{sh}}(z)=f_{\mathrm{sh}}(z) S_{\mathrm{A}, \mathrm{sh}, \mathrm{VIS}}(z)+f_{\mathrm{sh}}(z) S_{\mathrm{A}, \mathrm{sh}, \mathrm{NIR}}(z),
\end{aligned}
$$

where $f_{\mathrm{sl}}(z)$ and $f_{\mathrm{sh}}(z)$ are the fractions of leaf area for sunlit and shaded leaves respectively, with $f_{\mathrm{sl}}(z)+f_{\mathrm{sh}}(z)=1$. These two fractions are determined by the transmission coefficient of the beam component, $\tau_{\mathrm{b}}$ (see Appendix B):

$$
\begin{aligned}
& f_{\mathrm{sl}}(z)=\tau_{\mathrm{b}}, \\
& f_{\mathrm{sh}}(z)=1-\tau_{\mathrm{b}} .
\end{aligned}
$$

\subsection{Leaf-Level Energy Balance}

The energy balance at the leaf scale is used to calculate leaf surface temperature $T_{\mathrm{L}}$ (Campbell and Norman 1998), and using the linearization technique of Penman (1948), $T_{\mathrm{L}}$ is approximated as (Campbell and Norman 1998; Lai et al. 2000b):

$$
T_{\mathrm{L}}=T+\frac{S_{\mathrm{A}}-\varepsilon_{\mathrm{L}} \sigma T^{4}-L_{\mathrm{v}} \rho \frac{g_{\mathrm{b}} g_{\mathrm{s}, \mathrm{v}}}{g_{\mathrm{b}}+g_{\mathrm{s}, \mathrm{v}}} D}{C_{\mathrm{p}} \rho g_{\mathrm{b}}+L_{\mathrm{v}} \rho \frac{g_{\mathrm{b}} g_{\mathrm{s}, \mathrm{v}}}{g_{\mathrm{b}}+g_{\mathrm{s}, \mathrm{v}}}+C_{\mathrm{p}} \rho g_{\mathrm{r}}},
$$

where $D$ is the water vapour deficit $\left(\mathrm{kg} \mathrm{kg}^{-1}\right), C_{\mathrm{p}}$ is the specific heat of air $\left(\mathrm{J} \mathrm{mol}^{-1} \mathrm{~K}^{-1}\right), g_{\mathrm{r}}$ is the radiative conductance $\left(\mathrm{m} \mathrm{s}^{-1}\right), \sigma$ is the Stefan-Boltzman constant, and $g_{\mathrm{s}, \mathrm{v}}$ and $g_{\mathrm{b}, \mathrm{v}}$ are the stomatal and boundary-layer conductances $\left(\mathrm{mol} \mathrm{m}^{-2} \mathrm{~s}^{-1}\right)$ of water vapour, respectively, and $L_{v}$ is the latent heat of vaporization.

\subsection{Physiological Model and Photosynthesis}

The stomatal conductance for $\mathrm{CO}_{2}, g_{\mathrm{s}, \mathrm{c}}$, can be estimated from the physiological model of Collatz et al. (1991), originally proposed by Ball et al. (1987), given by

$$
g_{\mathrm{s}, \mathrm{c}}=m \frac{A_{\mathrm{n}} R H_{\mathrm{s}}}{C_{\mathrm{s}}}+b
$$

where $m$ and $b$ are parameters determined from gas-exchange measurements, $R H_{\mathrm{S}}$ and $C_{\mathrm{S}}$ are the relative humidity and $\mathrm{CO}_{2}$ concentration on the leaf surface, and $A_{\mathrm{n}}$ is the leaf net assimilation rate, which can be calculated from the $A_{\mathrm{n}}-C_{\mathrm{i}}$ curve after Farquhar et al. (1980), and given by 


$$
A_{\mathrm{n}}=\frac{\kappa_{1}\left(C_{\mathrm{i}}-\Gamma^{*}\right)}{C_{\mathrm{i}}+\kappa_{2}}-R_{\mathrm{d}} .
$$

Here $\kappa_{1}=\alpha_{\mathrm{p}} e_{\mathrm{m}} I_{\mathrm{p}}$ and $\kappa_{2}=2 \Gamma^{*}$ for light-limited photosynthesis, $\kappa_{1}=V_{\mathrm{cmax}}$ and $\kappa_{2}=$ $K_{\mathrm{C}}\left(1+O_{\mathrm{i}} / K_{\mathrm{O}}\right)$ for rubisco limited photosynthesis, $V_{\mathrm{cmax}}$ is the maximum catalytic capacity of rubisco per unit leaf area, $R_{\mathrm{d}}$ is the dark respiration rate, $\alpha_{\mathrm{p}}$ is the leaf absorptivity for PAR, $e_{\mathrm{m}}$ is the maximum quantum efficiency, $I_{\mathrm{p}}$ is the incident PAR flux density on the leaf surface, $\Gamma^{*}$ is the $\mathrm{CO}_{2}$ concentration in the absence of $R_{\mathrm{d}}, K_{\mathrm{C}}$ and $K_{\mathrm{O}}$ are Michaelis-Menten constants for $\mathrm{CO}_{2}$ fixation and for oxygen inhibition with respect to $\mathrm{CO}_{2}$, and $O_{\mathrm{i}}$ is the oxygen concentration (Campbell and Norman 1998; Katul et al. 2003; Lai et al. 2000a). $R_{\mathrm{d}}$ can be estimated from $V_{\mathrm{cmax}}$ after Farquhar et al. (1980):

$$
R_{\mathrm{d}}=\chi V_{\mathrm{cmax}}
$$

where $\chi=0.015$ for this stand (Campbell and Norman 1998; Ellsworth 2000; Juang et al. 2006). The temperature dependency of $V_{\mathrm{cmax}}(t, z)$ can be expressed as:

$$
V_{\mathrm{cmax}}=V_{\mathrm{cmax}, 25} \frac{\exp \left[a_{1}\left(T_{\mathrm{L}}-25\right)\right]}{1+\exp \left[a_{2}\left(T_{\mathrm{L}}-41\right)\right]}
$$

where $a_{1}$ and $a_{2}$ are the species-specific adjustment coefficients, which are obtained via porometry measurement and $V_{\mathrm{cmax}, 25}$ is the value of $V_{\mathrm{cmax}}$ at $25^{\circ} \mathrm{C}$ (Campbell and Norman 1998; Collatz et al. 1991; Farquhar et al. 1980). From previous studies conducted at the site (Ellsworth 1999; Naumburg and Ellsworth 2000; Naumburg et al. 2001), the average $V_{\mathrm{cmax}, 25}$, $a_{1}$ and $a_{2}$ are $59 \mu \mathrm{mol} \mathrm{m} \mathrm{m}^{-2} \mathrm{~s}^{-1}, 0.051$ and 0.205 , respectively, for the upper canopy pine foliage, and are $30 \mu \mathrm{mol} \mathrm{m}^{-2} \mathrm{~s}^{-1}, 0.088$ and 0.290 , respectively, for the sub-canopy broadleaved plants (Lai et al. 2002b). The seasonal acclimation of $V_{\mathrm{cmax}, 25}$, derived from leaf-gas exchange measurements collected over a 3-year period, was reported by Ellsworth (1999) to have an amplitude of about $18 \%$. The importance of this seasonal acclimation vis-à-vis resolving the two-way interaction between the leaves and their microclimate is discussed below.

\subsection{Combining the Sub-models: The CANVEG Framework}

Summing up, the CANVEG equations for an arbitrary layer within the canopy volume are as follows:

(1) The three mean scalar continuity equations for $\mathrm{CO}_{2}, \mathrm{H}_{2} \mathrm{O}$, and temperature provide three equations with nine unknowns (two mean scalar concentrations and one mean temperature, three turbulent scalar fluxes, and three scalar sources or sinks).

(2) The turbulent transport models (at any closure level) establish three additional equations linking turbulent fluxes to mean concentration (albeit the complexity of this expression varies with the closure scheme and can be affected by thermal stratification). Hence, the physical system alone combining mean scalar continuity and turbulent transport theories provides six equations with nine unknowns.

(3) The assumption that mass and heat transfer from the leaf surface (or stomatal pores) to the atmosphere is Fickian provides three additional equations that mathematically close the original system (nine equations with nine unknowns) at the expense of introducing four additional unknowns: the leaf stomatal conductance, and three internal or leaflevel mean concentration states (surface temperature, surface humidity, and internal $\mathrm{CO}_{2}$ concentration).

(4) The fact that the three scalars considered here are heat, water vapour, and $\mathrm{CO}_{2}$, permits the formulation of three independent equations based on leaf energy balance (for surface 
temperature), the Farquhar photosynthesis model (for inter-cellular $\mathrm{CO}_{2}$ concentration), the hydration state of the leaves (for linking internal water vapour concentration with surface temperature). Finally, the system is mathematically 'closed' via a semi-empirical stomatal conductance model for well-hydrated leaves (i.e. Eq. 17).

The WMA eliminates steps (1) and (2) in the above procedure because the scalar concentration is assumed constant inside the canopy (as is the case in virtually all forest growth and biogeochemical cycling models). Again, because leaf stomatal pores are assumed to be saturated (in step 4), drought conditions known to induce stomatal closure are excluded from the model-data comparisons here.

\subsection{Boundary Conditions}

Boundary conditions are needed to solve the governing equations. The long-term EC measurements at the canopy top are used to derive similarity expressions for the normalized standard deviation of the velocity components $u, v, w$, and the scalar quantities, $\theta, q, c$ as a function of the atmospheric stability parameter $\varsigma=\frac{z-d_{0}}{L}$, where $L$ is the Obukhov length. The similarity functions for different quantities and for different stability classes are shown in Fig. 2; the regression parameters obtained from a least squares analysis on these data are summarized in Table 1. Despite the fact that the measurements were collected in the roughness sublayer just above the canopy, they appear to be consistent with a number of field experiments in the atmospheric surface layer summarized by Stull (1988) and Kaimal and Finnigan (1994). The boundary conditions at the forest floor are given in Appendix C.

\section{Results and Discussion}

To address the two main questions here, the results and discussion are structured as follows: the seasonal variation in leaf area density and its effect on the main driver for scalar production and uptake inside the canopy (i.e, light levels) is first presented. Next, the modelled space-time variations of the scalar sources, sinks, and fluxes for the three closure models are presented to illustrate their dissimilarity inside the canopy at various times of the day and different days of the year. These dissimilarities are needed as a bridge to explain the differences in annual uptake or release of scalars by the canopy. With this background, the mean scalar concentration profile calculations using the three closure schemes are compared to the measurements (and to the calculations that employ the WMA). The computed scalar fluxes using the WMA and the three closure models are also compared with the EC-based flux measurements above the canopy. Statistical analyses of these model-model and model-data intercomparisons provide quantitative answers to the first question. The second question is addressed by contrasting two sets of model calculations conducted using the higher order closure version: one set accounts for the seasonal variations in $V_{c \max , 25}$, while the other does not (though the annual mean $V_{c \max , 25}$ is the same in both sets). The scalar flux differences at the canopy top between these two sets of calculations are then compared to their counterparts when employing model calculations that use the WMA. Discussions about the need to resolve thermal stratification inside the canopy are presented last.

\subsection{Radiation Environment Within the Canopy Volume}

The radiative components (PAR and net) directly influence leaf photosynthesis (described later) and leaf energy exchange (latent heat and sensible heat). Incident shortwave radiation 

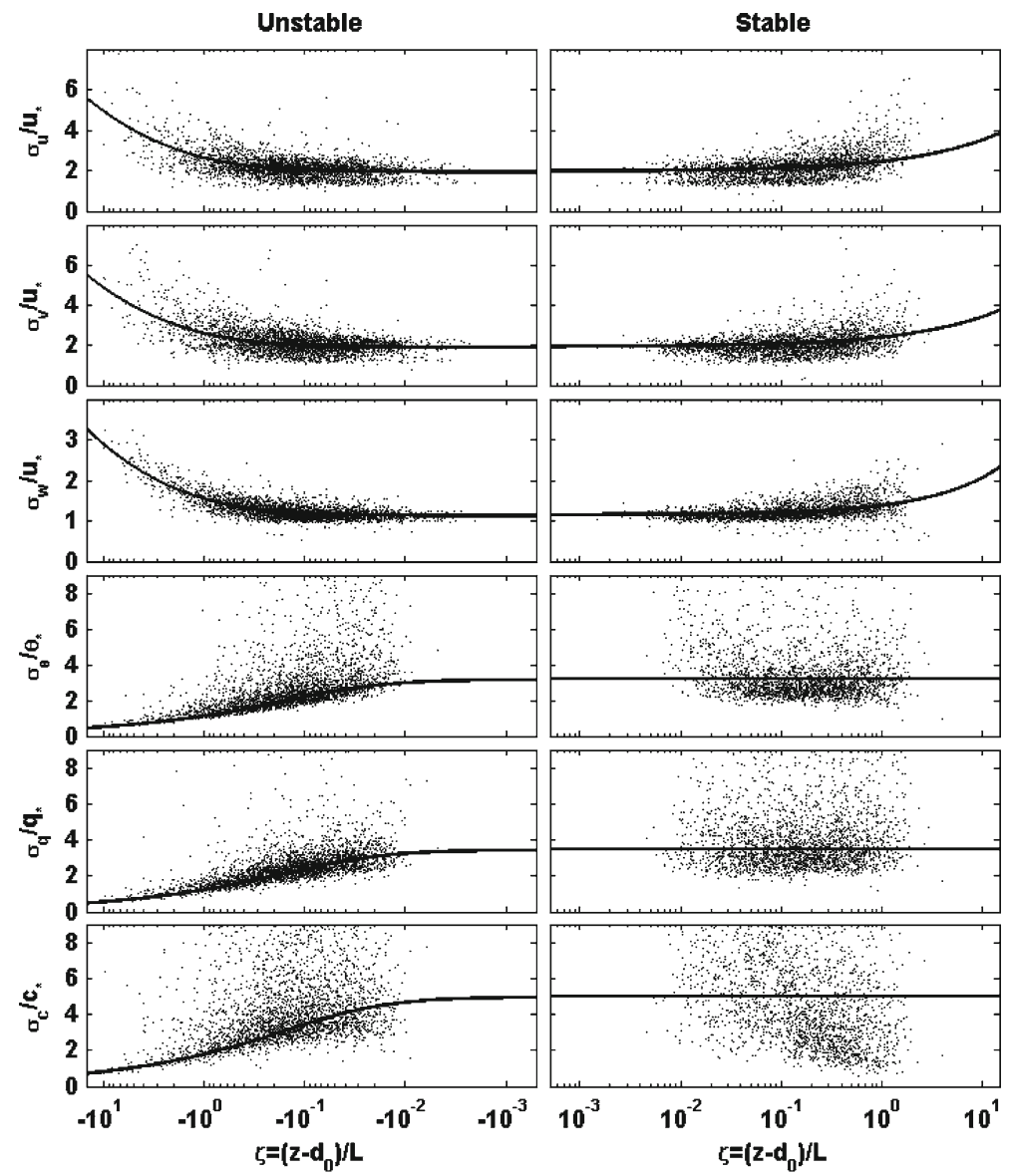

Fig. 2 Normalized standard deviation of the velocity components $u, u, w$, the scalar quantities, $\theta, q$, and $c$ for unstable (left column) and stable (right column) atmospheric stability conditions. All quantities are analyzed when the friction velocity at the canopy top exceeds $0.1 \mathrm{~m} \mathrm{~s}^{-1}$. The solid lines represent the regression curves whose parameters are summarized in Table 1

at the top of the canopy was not directly measured before 2004, so to estimate the incident shortwave radiation for earlier periods, a relationship between PAR (in $\mu \mathrm{mol} \mathrm{m}^{-2} \mathrm{~s}^{-1}$ ) and shortwave radiation (in $\mathrm{W} \mathrm{m}^{-2}$ ) measured by the Kipp \& Zonen CNR1 net radiometer installed at the top of the canopy (in the summer of 2003) was derived. This relationship is affected by zenith angle, location, and sky properties because the wavebands for PAR (in the spectral range of VIS, 400-700 nm) and shortwave radiation (VIS and NIR) are different. To convert units of PAR from $\mu \mathrm{molm} \mathrm{m}^{-2} \mathrm{~s}^{-1}$ to $\mathrm{W} \mathrm{m}^{-2}$, a mean waveband $=550 \mathrm{~nm}$ and a photon energy $=2.30 \times 10^{5} \mathrm{~J} \mathrm{~mol}^{-1}$ were used. The coefficient of determination $\left(R^{2}=0.99\right)$ between PAR and shortwave radiation measurements, shown in Fig. 3, suggests an excellent linear relationship although minor scatter remains due to cloudy conditions.

To illustrate how the canopy attenuates PAR throughout the day and across seasons, model results for PAR penetration ratios (i.e. the ratio of PAR at a given level zinside the canopy to the incident PAR at the top of the canopy) at midday (1200 LT) and in the morning (0800 LT) are shown in Fig. 4. The results are presented as 7-day moving averages for the entire year of 2005 for illustration. The normalized leaf area density profiles are shown for reference 
Table 1 The similarity function expressions for normalized standard deviation of the wind components $u, v$, $w$, and the scalar quantities, $\theta, q, c$, for different atmospheric stability conditions $\left(\varsigma=\left(z-d_{o}\right) / L\right)$

\begin{tabular}{|c|c|c|c|}
\hline Stability & Variable & Form & Constants \\
\hline Unstable & $\begin{array}{l}\sigma_{u} / u_{*} \\
\sigma_{v} / u_{*} \\
\sigma_{w} / u_{*} \\
\sigma_{\theta} / \theta_{*} \\
\sigma_{q} / q_{*} \\
\sigma_{c} / c_{*}\end{array}$ & $a(b+c \zeta)^{d}$ & $\begin{aligned} a & =1.95 ; b=1.0 ; c=-1.5 ; d=1 / 3 \\
a & =1.94 ; b=1.0 ; c=-1.5 ; d=1 / 3 \\
a & =1.15 ; b=1.0 ; c=-1.5 ; d=1 / 3 \\
a & =1.18 ; b=0.05 ; c=-1.0 ; d=-1 / 3 \\
a & =1.28 ; b=0.05 ; c=-1.0 ; d=-1 / 3 \\
a & =1.84 ; b=0.05 ; c=-1.0 ; d=-1 / 3\end{aligned}$ \\
\hline Stable & $\begin{array}{l}\sigma_{u} / u_{*} \\
\sigma_{v} / u_{*} \\
\sigma_{w} / u_{*} \\
\sigma_{\theta} / \theta_{*} \\
\sigma_{q} / q_{*} \\
\sigma_{c} / c_{*}\end{array}$ & $a+b \zeta^{d}$ & $\begin{array}{l}a=1.95 ; b=0.39 ; d=0.5 \\
a=1.94 ; b=0.37 ; d=0.5 \\
a=1.15 ; b=0.23 ; d=0.6 \\
c=3.20 \\
c=3.47 \\
c=5.00\end{array}$ \\
\hline Neutral & $\begin{array}{l}\sigma_{u} / u_{*} \\
\sigma_{v} / u_{*} \\
\sigma_{w} / u_{*} \\
\sigma_{\theta} / \theta_{*} \\
\sigma_{q} / q_{*} \\
\sigma_{c} / c_{*}\end{array}$ & $C$ & $\begin{aligned} c & =1.95 \\
c & =1.94 \\
c & =1.15 \\
c & =3.20 \\
c & =3.47 \\
c & =5.00\end{aligned}$ \\
\hline
\end{tabular}

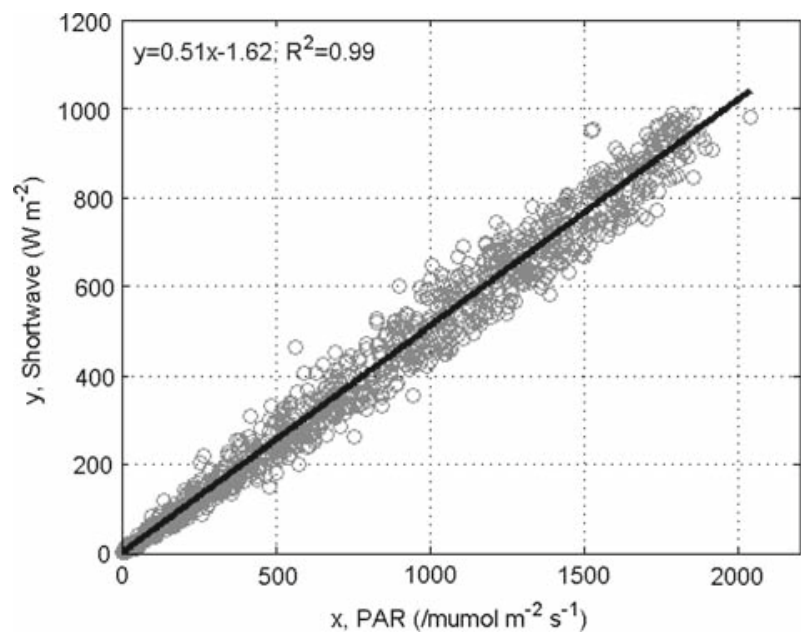

Fig. 3 The relationship between half-hourly measured photosynthetically active radiation (PAR) and measured incident shortwave radiation at the top of the canopy during the summer of 2003 (symbols). The regression equation (solid line), derived from 1235 half-hourly data points, is given by $y=0.51 x-1.62$, and the coefficient of determination $\left(R^{2}\right)$ is 0.99 . The theoretical slope for clear-sky conditions is 0.5

to illustrate their seasonal variations (and the contribution of the under-story dynamics). As expected, more PAR $(\approx 40 \%$ of the canopy top value) reaches the forest floor at midday in winter months (when LAI is minimum). However, less than $15 \%$ of the canopy top PAR 

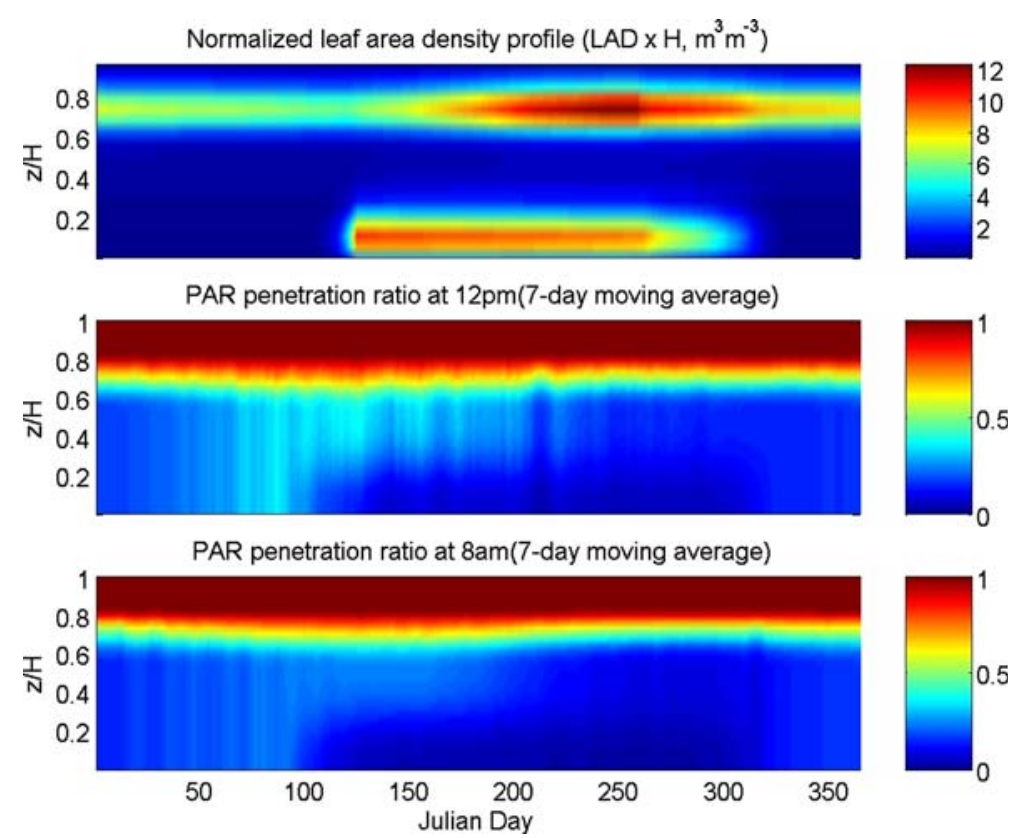

Fig. 4 The vertical variation of modelled PAR penetration ratio throughout the year at different times during the day (1200 LT and 0800 LT) during 2005. The upper panel shows the normalized leaf area density profiles (LAD) for reference

penetrates the canopy volume during the growing season, when LAI is at its maximum value. For integration of scalar fluxes to annual time scales, it is important to note that the understorey dynamics and PAR attenuation play an important role. Because of the low LAI in the pine stand during the spring, significant PAR arrives at the understorey levels for at least 2 months per year (e.g., see Julian days 130-180). Whether this understorey PAR contributes significantly to scalar fluxes is explored next.

\subsection{Scalar Source Strength and Flux Distribution}

Figure 5 shows the source (or sink) strength for different scalars at different times of day throughout the entire year of 2005 using the second-order closure model with atmospheric stability corrections as an example. For the $\mathrm{CO}_{2}$ source (or sink) strength, it is clear that while forest floor respiration dominates during nighttime conditions, the upper canopy becomes a strong sink during the day, especially during the growing season. The co-existence of both net carbon sinks and sources within the various canopy layers during the day is also evident during the winter season, and when the zenith angle is large (i.e., early morning and early evening). The model calculations suggest that the ecosystem is a large source of both latent and sensible heat during the growing season (as expected). Furthermore, it appears that canopy heating primarily occurs in the top one-third of the canopy where much of the radiation is intercepted by the main canopy foliage. The understorey sources and sinks of heat and water vapour appear much smaller than their pine counterpart. At noon, the understorey contributes to $\mathrm{CO}_{2}$ sequestration during the spring and early summer period, though its contribution during the remainder of the summer period appears minor. 


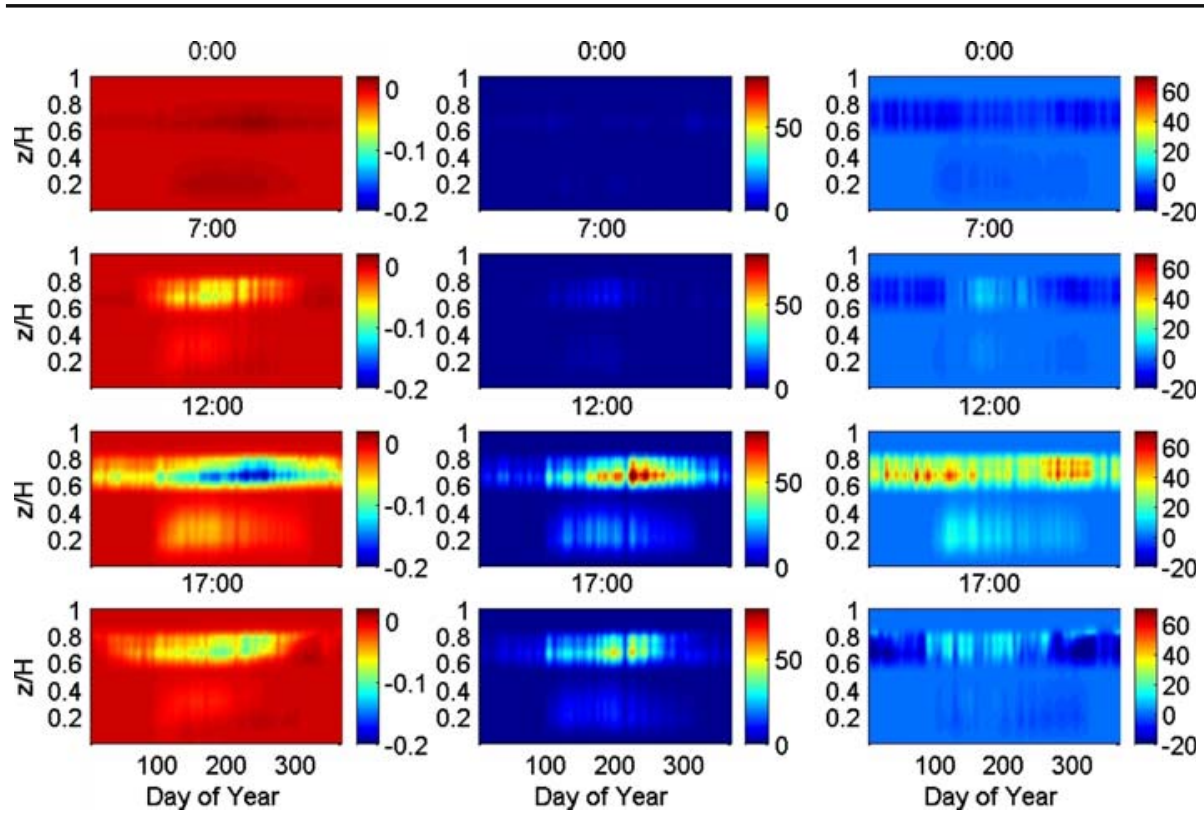

Fig. 5 The time-depth distributions of modelled $\mathrm{CO}_{2} \operatorname{sink} /$ source strength $\left(\mathrm{mgC} \mathrm{m}^{-3} \mathrm{~s}^{-1}\right.$, left column), latent heat source strength $\left(\mathrm{W} \mathrm{m}^{-3}\right.$, middle column), and sensible heat sink/source strength $\left(\mathrm{W} \mathrm{m}^{-3}\right.$, right column) at different times of day and different days of the year for 2005. All the model results shown here use the second-order closure scheme with atmospheric stability corrections

Figure 6 presents the simulated time-depth variations of the turbulent fluxes for the same time period shown in Fig. 5. These fluxes are computed by depth integrating the scalar sources (or sinks) and adding to this sum the scalar flux emitted (or absorbed) by the forest floor. Again, the $\mathrm{CO}_{2}$ flux distribution demonstrates that, while forest floor respiration is large, this ecosystem remains a net carbon sink throughout the year as verified by eddycovariance measurements. Also, Fig. 6 shows how the understorey plays a significant role in rapidly increasing $\mathrm{CO}_{2}$ uptake from the atmosphere during the early spring period, but its relative impact on water vapour and sensible heat fluxes during this same period appears less significant.

\subsection{Comparison Between Different Closure Approximations}

The ensemble-averaged scalar profiles (mean air temperature, mean water vapour concentration, and mean $\mathrm{CO}_{2}$ concentration) within the canopy volume for all the three closure schemes (i.e. first-order to third-order) and over different time periods in year 2005 are shown in Fig. 7. The WMA and the scalar profile measurements are also presented for reference. The comparisons in Fig. 7 demonstrate that second- and third-order closure schemes best agree with the mean concentration (or temperature) profile measurements for all three scalars. Furthermore, the analysis here suggests that there is no gain in predictive skills by increasing the closure from second-order to third-order as these two model results are almost indistinguishable (Fig. 7). The main scalar concentration differences emerge when comparing the results from these two higher-order closure schemes with the first-order closure model calculations. Table 2 summarizes the relative standard deviation (RSD, in percentage) when comparing different closure approximations with the scalar profile measurements. 


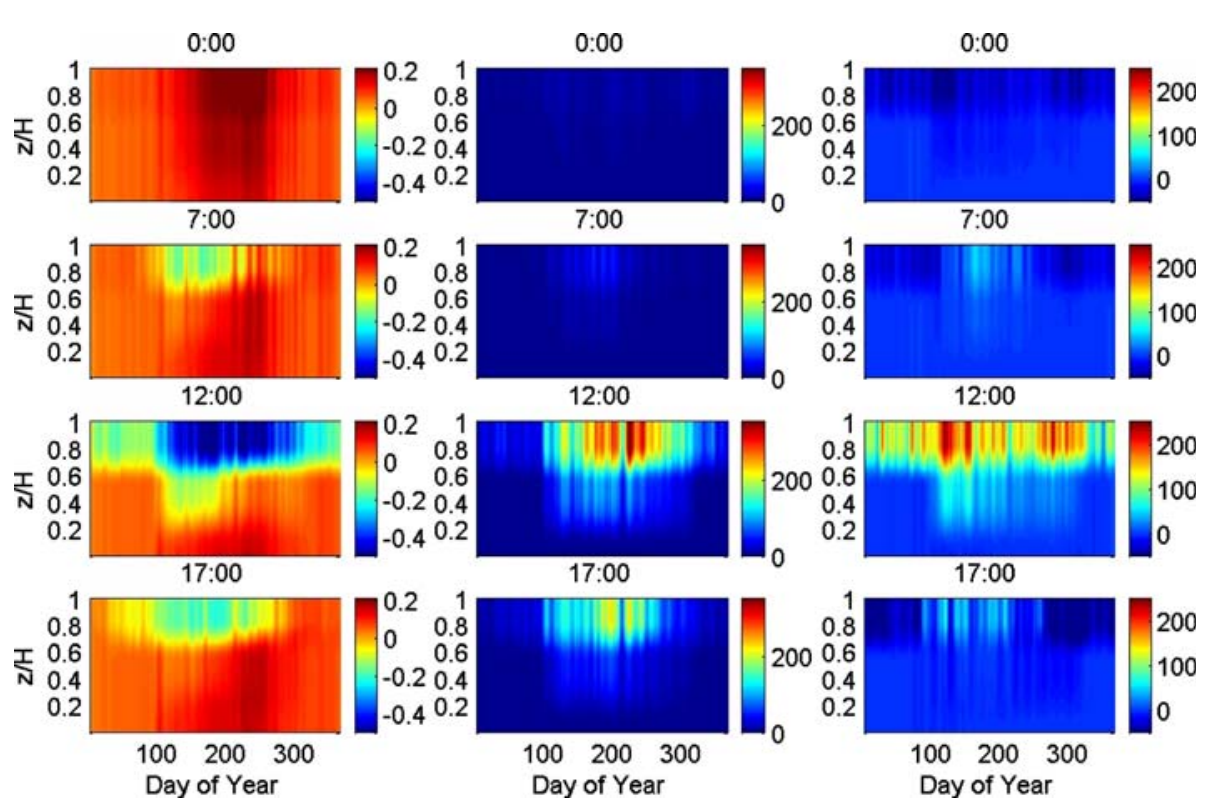

Fig. 6 The time-depth distributions of $\mathrm{CO}_{2}$ fluxes $\left(\mathrm{mgCm}^{-2} \mathrm{~s}^{-1}\right.$, left column), latent heat fluxes $\left(\mathrm{W} \mathrm{m}^{-2}\right.$, middle column), and sensible heat fluxes $\left(\mathrm{W} \mathrm{m}^{-2}\right.$, right column) at different times of day and different days of the year for 2005. All the model results shown here use the second-order closure scheme with atmospheric stability corrections

These data-model comparisons, shown in Fig. 7, suggest that higher-order closure approximations (order 2 or more) are needed if accurate mean scalar profiles inside the canopy are desired. The follow-up question is whether the predictive skills in modelling scalar sources (or sinks) and fluxes significantly improve by increasing the order of the closure scheme (as is the case for the scalar concentration and temperature). Recall that the two-way interaction between the canopy and its micro-environment is better resolved with higher-order closure schemes.

Figure 8 presents the ensemble-averaged hourly comparisons for the scalar fluxes (sensible and latent heat fluxes, and $\mathrm{CO}_{2}$ fluxes) at the top of canopy for the all closure models (in year 2005). Differences in nocturnal fluxes are very small among all the models, but during daytime conditions, differences between the models (and data) become significant. The reason the modelled $\mathrm{CO}_{2}$ fluxes above the canopy all agree with each other at night is due to the fact that these fluxes are dominated by the forest floor respiration $(\approx 70 \%$ of the flux at the canopy top). This forest floor respiration is a lower boundary condition identically imposed on all the models. However, as noted earlier, linking this flux boundary condition at the ground to $\mathrm{CO}_{2}$ concentration becomes sensitive to the turbulence representation, which is significantly different among the models.

All closure models overestimate the EC measured sensible heat and $\mathrm{CO}_{2}$ fluxes at night. For the sensible heat, it is difficult to separate all the possible factors. These factors may include parameterization of the longwave radiation inside the canopy, the small mean wind speeds inside the canopy that lead to small boundary-layer conductance, and hence, small errors in this conductance leads to large errors in leaf temperature, and the fact that the sensible heat affects both the fluid and scalar transport equations so that errors in the flow parameterization can also affect the sensible heat flux. It is difficult to attribute the data-model 
---1 st -2 2nd -.". 3rd $\ldots . . .$. Const. o Meas.
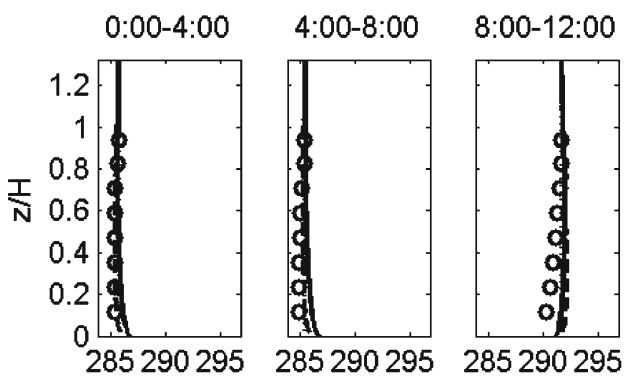

12:00-16:00 16:00-20:00

20:00-24:00
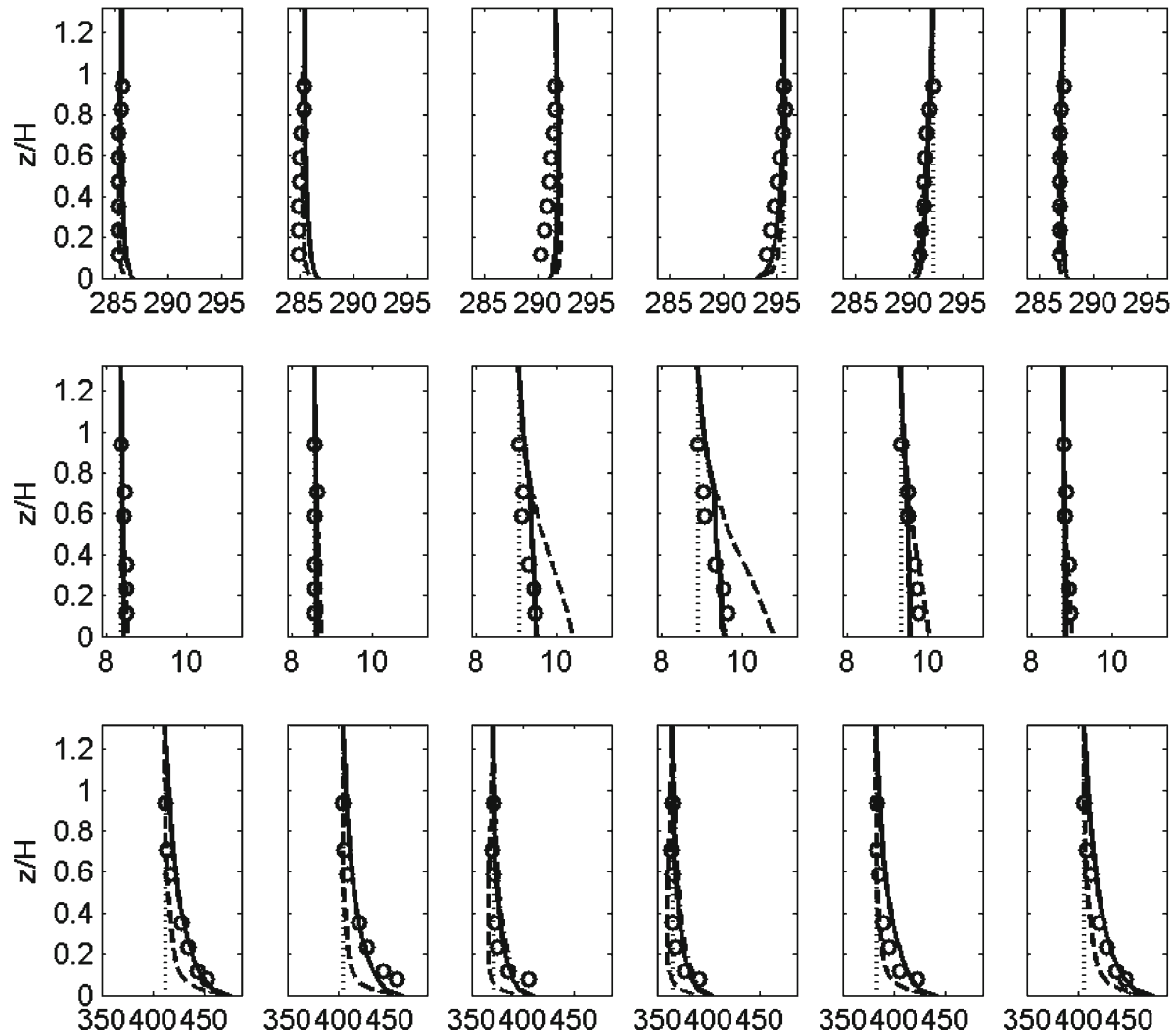

Fig. 7 Ensemble-averaged profiles of mean air temperature (K, upper panel), mean water vapour concentration ( $\mathrm{g} \mathrm{kg}^{-1}$, middle panel), and mean $\mathrm{CO}_{2}$ concentration ( $\mathrm{ppm}$, lower panel) for different closure approximations over different times of day in 2005. Model results include the atmospheric stability corrections. Note that the model results for the second- and third-order closure schemes are almost indistinguishable. The WMA is shown as vertical dotted lines

difference to a single cause. For $\mathrm{CO}_{2}$, the overestimation by the model is not too different from the underestimation expected by the EC measurements at night (even when the storage flux is small). The fact that EC measurements tend to underestimate nighttime $\mathrm{CO}_{2}$ fluxes, as discussed extensively for this site by Juang et al. (2006), suggests that the overestimation by the model is reasonable.

The relative standard deviations in Table 2 demonstrate that higher-order closure schemes perform significantly better than zeroth- and first-order closure models, especially for sensible and latent heat fluxes. Note that the value of the modelled sensible heat flux changes sign earlier in the afternoon when using the well-mixed assumption. This can have significant impact on calculations of convective boundary-layer height and triggers of convective rainfall (Juang et al. 2007a,b). Whether such differences in model performances inject flux biases at ecologically relevant time scales (i.e. annual and longer) is explored next. 
Table 2 The average relative standard deviation (in \%) for all model results when compared with the halfhourly eddy-covariance and canopy scalar profile measurements. 'With stability' refers to model results that resolve the effects of atmospheric stability within the canopy volume

\begin{tabular}{|c|c|c|c|c|c|}
\hline & \multirow[t]{2}{*}{$\begin{array}{l}\text { First-order } \\
\text { closure }\end{array}$} & \multicolumn{2}{|c|}{$\begin{array}{l}\text { Second-order } \\
\text { closure }\end{array}$} & \multicolumn{2}{|c|}{$\begin{array}{l}\text { Third-order } \\
\text { closure }\end{array}$} \\
\hline & & $\begin{array}{l}\text { With } \\
\text { stability }\end{array}$ & $\begin{array}{l}\text { Without } \\
\text { stability }\end{array}$ & $\begin{array}{l}\text { With } \\
\text { stability }\end{array}$ & $\begin{array}{l}\text { Without } \\
\text { stability }\end{array}$ \\
\hline Air temperature profiles & 16.3 & 11.8 & 14.3 & 11.3 & 14.0 \\
\hline Water vapour concentration profiles & 10.1 & 5.6 & 7.2 & 6.0 & 7.7 \\
\hline $\mathrm{CO}_{2}$ concentration profiles & 21.5 & 14.0 & 16.7 & 13.6 & 16.0 \\
\hline Sensible heat flux at top of canopy & 12.3 & 7.4 & 10.0 & 7.8 & 10.3 \\
\hline Latent heat flux at top of canopy & 16.7 & 11.2 & 15.8 & 11.8 & 16.1 \\
\hline Carbon flux at top of canopy & 23.0 & 17.7 & 20.2 & 17.4 & 19.8 \\
\hline
\end{tabular}
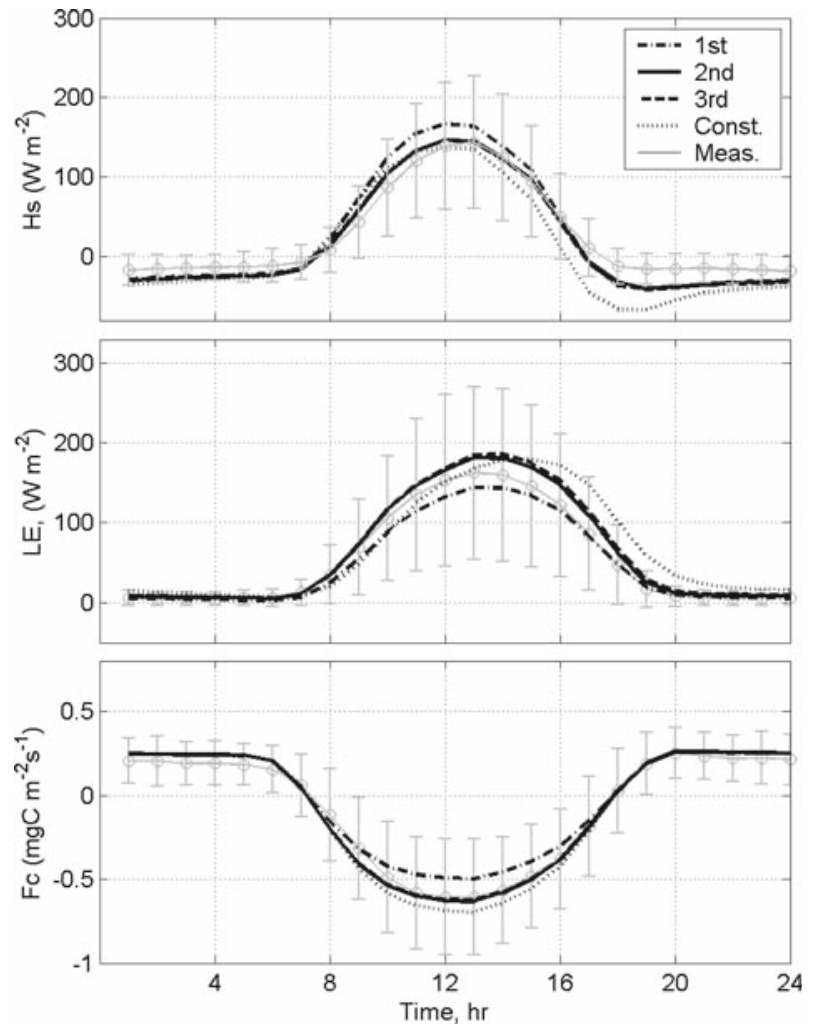

Fig. 8 Hourly ensemble-averaged measured (open circles) and modelled (lines) sensible heat flux $\left(H_{S}\right)$, latent heat flux $\left(L_{\mathrm{V}} E\right)$ and carbon dioxide flux $\left(F_{C}\right)$ at the top of the canopy in 2005. The model results were derived using different closure approximations (first-order to third-order) as well as the WMA for scalars. Ensemble averaging was conduced across each hour of day in 2005. Vertical bars represent one standard deviation around the ensemble-averaged eddy covariance measurements 


\subsection{Estimations of Annual NEE and ET}

The main objective is to explore how the two-way interaction between leaves and their microenvironment affects ecosystem annual net ecosystem $\mathrm{CO}_{2}$ exchange (NEE) and evapotranspiration (ET), and whether resolving this two-way interaction is as important as resolving the seasonality in key physiological parameters. From previous discussions, the second-order closure scheme was shown to optimally reproduce the mean scalar concentration (and temperature) profiles and fluxes; its predictive skills were also comparable to the computationally more-expensive third-order closure scheme. Hereafter, the second-order closure model with atmospheric stability corrections is used as a 'reference model' for resolving the two-way interaction between leaves and their microenvironment.

As earlier stated, $V_{\mathrm{cmax}, 25}$ of the pine foliage is known to vary seasonally for a number of reasons including temperature acclimation, age, and leaf nitrogen changes. Detailed leaf-level gas-exchange measurements reported by Ellsworth (1999) and inverse-model calculations reported in Juang et al. (2006) suggest that seasonal variations in $V_{\mathrm{cmax}, 25}$ of pine foliage can be approximated by a sinusoidal function given as

$$
\frac{V_{\mathrm{cmax}, 25}}{\left[V_{\mathrm{cmax}, 25}\right]_{\text {annual }}}=0.18 \sin \left[2 \pi\left(\frac{x-120}{365}\right)\right] \text {. }
$$

where $x$ is the day of the year. The annual NEE (from 2001 to 2005) derived from model calculations with a fixed $V_{\mathrm{cmax}, 25}$ (= to the mean value) and the sinusoidally varying $V_{\mathrm{cmax}, 25}$ are compared in Fig. 9. Although differences in annual NEE values between these two model results are small $(<5 \%)$, some differences in the patterns at different times of year are discernable. For our purposes, the effect of non-stationarity (i.e. sinusoidal variations) in $V_{\text {cmax,25 }}$ on annual NEE fluxes appears relatively minor (because of partial cancellations at the seasonal scales), at least when compared to biases in annual NEE introduced by using the WMA.

Figure 9 also compares model results derived from the WMA with the EC measurements for the years 2001-2005. While the comparison for all 5 years is shown, the discussion is limited to the wet years (2001, 2004, and 2005). Recall that year 2002 experienced a severe drought during the entire growing season (resulting in leaf area reduction in the pine stand), and the forest floor respiration in 2003 was dramatically different because of excess branches and litter produced by the damage from the ice storm in December of 2002. It suffices to note that annual NEE was overestimated by the reference model in years 2002 and 2003 for these two reasons. However, because the forest floor evaporation is much less sensitive to increased respiring biomass in 2003, good agreement between ET predictions and EC measurements were observed, in contrast to the poor agreement between EC-measured and modelled NEE.

Figure 9 also suggests that (i) the WMA model always predicts higher annual NEE $(\approx 6.6 \%)$ and ET $(\approx 8.3 \%)$ when compared to the second-order closure model, and this overestimation appears larger than the annual flux adjustments obtained by resolving the $18 \%$ variation in $V_{\mathrm{cmax}, 25}$.

\subsection{The Effect of Atmospheric Stability}

Having demonstrated that the two-way coupling between the vegetation and its microenvironment is well reproduced by the second-order closure model, we explore next whether non-adiabatic simplifications may still yield good agreements with the EC measurements. Resolving the adiabatic conditions inside the canopy at every level requires an iterative scheme for every 30-min simulation run because the velocity and scalar transfer equations 

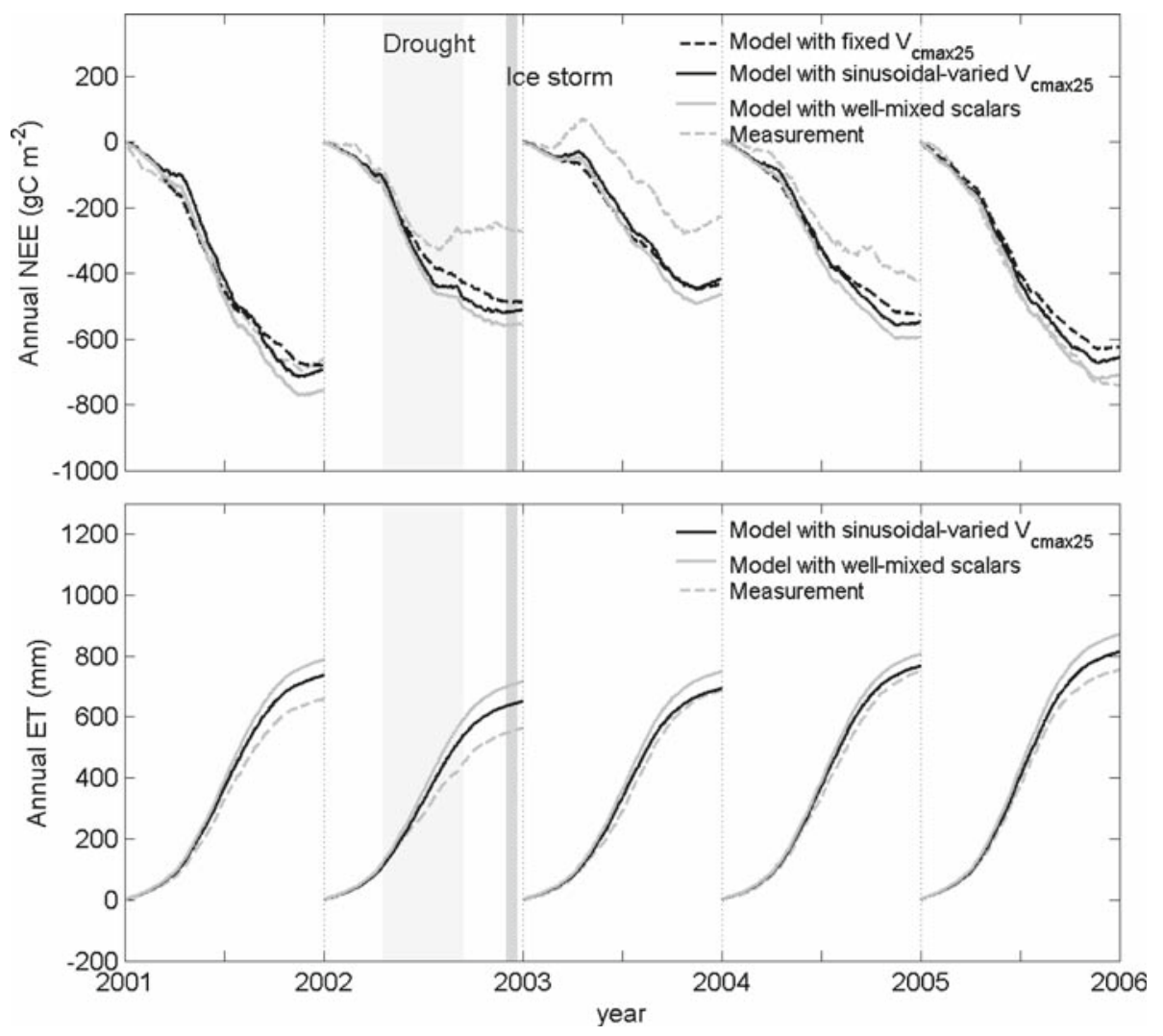

Fig. 9 Measured and modelled annual net ecosystem exchange (NEE, upper panel) and annual evapotranspiration (ET, lower panel). Model calculations are presented for the second-order closure scheme with atmospheric stability but (i) with a constant $V_{c \max , 25}$, (ii) a sinusoidal-varied $V_{c \max , 25}$. Model calculations assuming wellmixed scalar profiles inside the canopy are also shown. The eddy-covariance measurements from 2001 to 2005 are presented as well

must be simultaneously solved. A non-adiabatic simplification permits us to 'de-couple' the solution of the flow field from the scalar transfer calculations, as was done earlier by Baldocchi (1992), Baldocchi and Meyers (1998), and Lai et al. (2000a,b) in their Lagrangian CANVEG simulations. A previous field experiment in a deciduous forest at Camp Borden in Canada described by Shaw et al. (1988) reported that the effect of thermal stratification inside the canopy on the flow statistics can be as important as the effect of leaf area index variations. Whether this result holds for the pine forest here remains to be explored.

Table 2 summarizes the model-data comparisons when considering the effects of atmospheric stability and when neglecting them. Accounting for atmospheric stability improves the modelled relative standard deviations by $10-25 \%$ for mean scalar concentration (and temperature) profiles and turbulent fluxes at the top of the canopy. The effect of atmospheric stability on annual NEE and ET is also explored in Fig. 10. The annual NEE comparisons suggest that assuming a neutral atmosphere degrades the modelled NEE by roughly $12-15 \%$. For the annual ET, the model degradation is between 9 and $13 \%$. Hence, atmospheric stability corrections can improve model performance by about $10 \%$ or more, on average. 

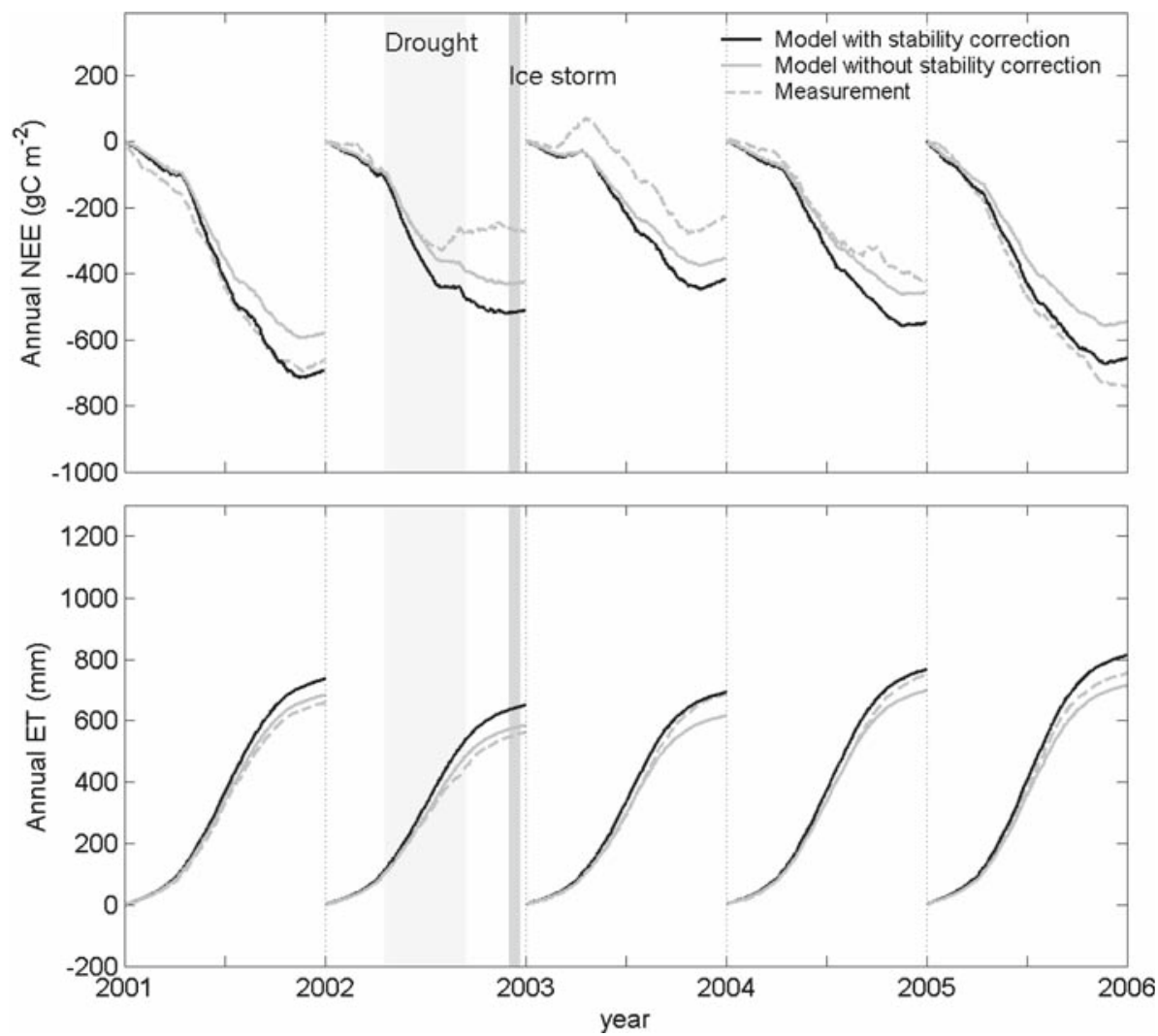

Fig. 10 Annual net ecosystem exchange (NEE, upper panel) and annual evapotranspiration (ET, lower panel) computed from the second-order closure model with and without atmospheric stability corrections. The EC measurements collected from 2001 to 2005 are repeated here for reference

\section{Summary and Conclusions}

The study objectives sought answers to two interrelated questions via model calculations and long-term measurements of mean scalar concentration and temperature profiles and eddycovariance scalar fluxes above the canopy. These questions were, (i) how detailed must the turbulent transport model be to resolve the two-way interaction between leaves and their microclimate? and (ii) what were the predictive skills gained by resolving this two-way interaction vis-à-vis correcting for seasonality in key physiological parameters (chosen here as $V_{\mathrm{cmax}, 25}$ )? To address the first question, a number of turbulent models were used ranging from zeroth-order (well-mixed assumption) to third-order closure. To address the second question, model calculations using a non-stationary $V_{\mathrm{cmax}, 25}$ were compared to model calculations with a constant $V_{\mathrm{cmax}, 25}$ case (though both have the same annual mean $V_{\mathrm{cmax}, 25}$ ). We found that:

(1) First-order closure modelling captures much of the scalar source-sink variations within the canopy as well as scalar fluxes above the canopy (to within 15\%); however, secondorder closure models were necessary to reproduce the mean scalar concentration (and temperature) profiles within the canopy (to within 8-15\%). 
(2) Third-order closure models perform no better than their second-order counterparts in terms of overall predictive skills for scalar concentration profiles and fluxes, though they were computationally much more demanding.

(3) The vertical flux most sensitive to the well-mixed assumption is sensible heat with a clear bias in the afternoon periods. This bias can have important consequences when modelling boundary-layer development and estimating the triggers of convective rainfall (Juang et al. 2007a,b).

(4) The comparison between measured and modelled annual NEE and ET using static and dynamic $V_{\mathrm{cmax}, 25}$ do not show significant differences $(\approx 5 \%)$. However, for shorter integration periods (e.g., 1 month or one season), the $\mathrm{CO}_{2}$ flux can be sensitive to variations in $V_{\mathrm{cmax}, 25}$. This conclusion may not be general for all forest species, but indicative that seasonal perturbations of $c a .20 \%$ around the annual mean in physiological parameters do not bias mean annual fluxes. However, assuming a well-mixed concentration (and temperature) can bias annual fluxes in this forested ecosystem by more than $5 \%$.

(5) Changes in near-surface atmospheric stability have significant effects (10-20\%) on the scalar concentration profile distributions inside the canopy and scalar flux estimates at the top of the canopy. The calculation of annual NEE and ET suggests that assuming a non-neutral atmosphere can be more important than resolving the $18 \%$ amplitude variation in $V_{\mathrm{cmax}, 25}$ for this evergreen forest, as long as the mean $V_{\mathrm{cmax}, 25}$ is not biased.

Acknowledgements The authors thank Ross McMurtrie for the helpful discussions on the use of WMA in forest growth models. This study was supported, in part, by US Department of Energy (DOE) through the Office of Biological and Environmental Research (BER), Terrestrial Carbon Processes (TCP) program (Grants \# 10509-0152, DE-FG02-00ER53015, and DE-FG02-95ER62083), the National Science Foundation (NSF-EAR 0628342 and 0635787), and the Bi-national Agricultural Research and Development (BARD) Fund (IS-3861-96).

\section{Appendix A: Closure Approximation}

\section{A.1 Second-order Closure Parameterization for Triple Correlations}

The triple correlation terms of the turbulent velocity components for the second-order closure model are represented as (Katul and Albertson 1998; Mellor 1973):

$$
\left\langle\overline{u_{\mathrm{i}}^{\prime} u_{\mathrm{j}}^{\prime} u_{\mathrm{k}}^{\prime}}\right\rangle=-Q \lambda_{1}\left(\frac{\partial\left\langle\overline{u_{\mathrm{i}}^{\prime} u_{\mathrm{j}}^{\prime}}\right\rangle}{\partial x_{\mathrm{k}}}+\frac{\partial\left\langle\overline{u_{\mathrm{j}}^{\prime} u_{\mathrm{k}}^{\prime}}\right\rangle}{\partial x_{\mathrm{i}}}+\frac{\partial\left\langle\overline{u_{\mathrm{k}}^{\prime} u_{\mathrm{i}}^{\prime}}\right\rangle}{\partial x_{\mathrm{j}}}\right) .
$$

Similarly, the second-order closure approximation for the turbulent transport of scalar fluxes and buoyant terms can be expressed as

$$
\begin{aligned}
& \left\langle\overline{u_{\mathrm{i}}^{\prime} u_{\mathrm{j}}^{\prime} \zeta^{\prime}}\right\rangle=-Q \lambda_{1}\left(\frac{\partial\left\langle\overline{u_{\mathrm{j}}^{\prime} \zeta^{\prime}}\right\rangle}{\partial x_{\mathrm{i}}}+\frac{\partial\left\langle\overline{u_{\mathrm{i}}^{\prime} \zeta^{\prime}}\right\rangle}{\partial x_{\mathrm{j}}}\right), \\
& \left\langle\overline{u_{\mathrm{i}}^{\prime} T^{\prime} \zeta^{\prime}}\right\rangle=-Q \lambda_{1}\left(\frac{\partial\left\langle\overline{T^{\prime} \zeta^{\prime}}\right\rangle}{\partial x_{\mathrm{i}}}\right) .
\end{aligned}
$$




\section{A.2 Third-order Closure Parameterization}

The closure expression for the triple correlation terms in Eq. 12 is derived from a simplified steady-state budget described in Meyers and Paw (1986):

$$
\begin{aligned}
\frac{\partial\left\langle\overline{u_{\mathrm{i}}^{\prime} u_{\mathrm{j}}^{\prime} w^{\prime}}\right\rangle}{\partial t}= & -\left\langle\overline{u_{\mathrm{i}}^{\prime} w^{\prime} w^{\prime}}\right\rangle \frac{\partial\left\langle\overline{u_{\mathrm{j}}}\right\rangle}{\partial z}-\left\langle\overline{u_{\mathrm{j}}^{\prime} w^{\prime} w^{\prime}}\right\rangle \frac{\partial\left\langle\overline{u_{\mathrm{i}}}\right\rangle}{\partial z}-\left\langle\overline{w^{\prime} w^{\prime}}\right\rangle \frac{\partial\left\langle\overline{u_{\mathrm{i}}^{\prime} u_{\mathrm{j}}^{\prime}}\right.}{\partial z} \\
& -\left\langle\overline{u_{\mathrm{i}}^{\prime} w^{\prime}}\right\rangle \frac{\partial\left\langle\overline{w^{\prime} u_{\mathrm{j}}^{\prime}}\right\rangle}{\partial z}-\left\langle\overline{u_{\mathrm{j}}^{\prime} w^{\prime}}\right\rangle \frac{\partial\left\langle\overline{w^{\prime} u_{\mathrm{i}}^{\prime}}\right\rangle}{\partial z}-\left\langle\overline{u_{\mathrm{i}}^{\prime} u_{\mathrm{j}}^{\prime} \frac{\partial p^{\prime}}{\partial z}}\right\rangle-\left\langle\overline{u_{\mathrm{i}}^{\prime} w^{\prime} \frac{\partial p^{\prime}}{\partial z}}\right\rangle \\
& -\left\langle\overline{u_{\mathrm{j}}^{\prime} w^{\prime} \frac{\partial p^{\prime}}{\partial z}}\right\rangle-\left\langle\overline{u_{\mathrm{i}}^{\prime} w^{\prime}}\right\rangle\left\langle\overline{\frac{\partial p^{\prime}}{\partial x_{\mathrm{j}}}}\right\rangle-\left\langle\overline{u_{\mathrm{j}}^{\prime} w^{\prime}}\right\rangle\left\langle\overline{\frac{\partial p^{\prime}}{\partial x_{\mathrm{i}}}}\right\rangle-M_{\mathrm{ij} 3}=0,
\end{aligned}
$$

where $M_{\mathrm{ij} 3}$ is the dissipation rate and is expressed as:

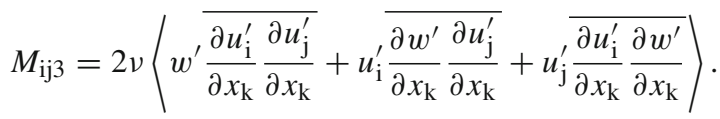

A simplified return-to-isotropic model introduced by Andre et al. (1981) is applied to parameterize the pressure and molecular terms in Eq. 24

$$
\left\langle\overline{u_{\mathrm{i}}^{\prime} u_{\mathrm{j}}^{\prime} \frac{\partial p^{\prime}}{\partial z}}\right\rangle+\left\langle\overline{u_{\mathrm{i}}^{\prime} w^{\prime} \frac{\partial p^{\prime}}{\partial z}}\right\rangle+\left\langle\overline{u_{\mathrm{j}}^{\prime} w^{\prime} \frac{\partial p^{\prime}}{\partial z}}\right\rangle+M_{\mathrm{ij} 3}=\frac{C_{8}\left\langle\overline{u_{\mathrm{i}}^{\prime} u_{\mathrm{j}}^{\prime} w^{\prime}}\right\rangle}{\tau} .
$$

After rearranging equations 24 and 26, the general form of the triple correlation terms can be represented as:

$$
\begin{aligned}
\left\langle\overline{u_{\mathrm{i}}^{\prime} u_{\mathrm{j}}^{\prime} w^{\prime}}\right\rangle= & -\frac{\tau}{C_{8}}\left(\left\langle\overline{u_{\mathrm{i}}^{\prime} w^{\prime} w^{\prime}}\right\rangle \frac{\partial\left\langle\overline{u_{\mathrm{j}}}\right\rangle}{\partial z}+\left\langle\overline{u_{\mathrm{j}}^{\prime} w^{\prime} w^{\prime}}\right\rangle \frac{\partial\left\langle\overline{u_{\mathrm{i}}}\right\rangle}{\partial z}\right. \\
& \left.+\left\langle\overline{w^{\prime} w^{\prime}}\right\rangle \frac{\partial\left\langle\overline{u_{i}^{\prime} u_{j}^{\prime}}\right\rangle}{\partial z}+\left\langle\overline{u_{\mathrm{i}}^{\prime} w^{\prime}}\right\rangle \frac{\partial\left\langle\overline{w^{\prime} u_{\mathrm{j}}^{\prime}}\right\rangle}{\partial z}+\left\langle\overline{u_{\mathrm{j}}^{\prime} w^{\prime}}\right\rangle \frac{\partial\left\langle\overline{w^{\prime} u_{\mathrm{i}}^{\prime}}\right\rangle}{\partial z}\right) .
\end{aligned}
$$

Likewise, the steady-state expression for the triple correlation terms in the scalar term and temperature fluctuation can be derived following the same procedure described in Meyers and Paw (1987) to yield: 


$$
\begin{aligned}
\left\langle\overline{u_{\mathrm{i}}^{\prime} u_{\mathrm{j}}^{\prime} \zeta^{\prime}}\right\rangle= & -\frac{\tau}{C_{8}}\left(\left\langle\overline{u_{\mathrm{i}}^{\prime} u_{\mathrm{j}}^{\prime} w^{\prime}}\right\rangle \frac{\partial\langle\bar{\zeta}\rangle}{\partial z}+\left\langle\overline{w^{\prime} u_{\mathrm{j}}^{\prime} \zeta^{\prime}}\right\rangle \frac{\partial\left\langle\overline{u_{\mathrm{i}}}\right\rangle}{\partial z}+\left\langle\overline{w^{\prime} u_{\mathrm{i}}^{\prime} \zeta^{\prime}}\right\rangle \frac{\partial\left\langle\overline{u_{\mathrm{j}}}\right\rangle}{\partial z}\right. \\
& \left.+\left\langle\overline{w^{\prime} u_{\mathrm{i}}^{\prime}}\right\rangle \frac{\partial\left\langle\overline{u_{\mathrm{j}}^{\prime} \zeta^{\prime}}\right\rangle}{\partial z}+\left\langle\overline{w^{\prime} u_{\mathrm{j}}^{\prime}}\right\rangle \frac{\partial\left\langle\overline{u_{\mathrm{i}}^{\prime} \zeta^{\prime}}\right\rangle}{\partial z}+\left\langle\overline{w^{\prime} \zeta^{\prime}}\right\rangle \frac{\partial\left\langle\overline{u_{\mathrm{i}}^{\prime} u_{\mathrm{j}}^{\prime}}\right\rangle}{\partial z}\right),
\end{aligned}
$$

and

$$
\begin{aligned}
\left\langle\overline{u_{\mathrm{i}}^{\prime} T^{\prime} \zeta^{\prime}}\right\rangle= & -\frac{\tau}{C_{8}}\left(\left\langle\overline{w^{\prime} u_{\mathrm{i}}^{\prime} \zeta^{\prime}}\right\rangle \frac{\partial\langle\bar{T}\rangle}{\partial z}+\left\langle\overline{w^{\prime} u_{\mathrm{i}}^{\prime} T^{\prime}}\right\rangle \frac{\partial\langle\bar{\zeta}\rangle}{\partial z}+\left\langle\overline{w^{\prime} T^{\prime} \zeta^{\prime}}\right\rangle \frac{\partial\left\langle\overline{u_{\mathrm{i}}}\right\rangle}{\partial z}\right. \\
& \left.+\left\langle\overline{w^{\prime} u_{\mathrm{i}}^{\prime}}\right\rangle \frac{\partial\left\langle\overline{T^{\prime} \zeta^{\prime}}\right\rangle}{\partial z}+\left\langle\overline{w^{\prime} T^{\prime}}\right\rangle \frac{\partial\left\langle\overline{u_{\mathrm{i}}^{\prime} \zeta^{\prime}}\right\rangle}{\partial z}+\left\langle\overline{w^{\prime} \zeta^{\prime}}\right\rangle \frac{\partial\left\langle\overline{u_{\mathrm{i}}^{\prime} T^{\prime}}\right\rangle}{\partial z}\right)
\end{aligned}
$$

For lower boundary conditions, vertical gradients in the triple moments were assumed to be zero at the forest floor.

\section{Appendix B: Light Attenuation Model}

\section{B.1 Partitioning of Incoming Shortwave Radiation}

The incoming shortwave radiation received by the surface is composed of two portions: beam $S_{\mathrm{b} 0}$ and diffuse $S_{\mathrm{d} 0}$ components. To quantify the partitions of $S_{\mathrm{b} 0}$ and $S_{\mathrm{d} 0}$, the atmospheric transmissivity (or clearness index) $K_{\mathrm{a}}$ needs to be determined, and estimated as

$$
K_{\mathrm{a}}=\frac{S_{0}}{S_{\mathrm{sc}} \sin \beta}
$$

where $S_{0}$ is the measured incident radiation on the surface, $S_{\mathrm{sc}}$ is the solar radiative flux density normal to the solar beam outside the atmosphere, and $\sin \beta$ is the solar elevation (Erbs et al. 1982; Goudriaan and van Laar 1994; Leuning et al. 1995).

Once $K_{\mathrm{a}}$ is determined from $S_{0}$, the fraction of diffuse component $f_{\mathrm{d}}=S_{\mathrm{d} 0} / S_{0}$ can be quantified based on the experimental relationship by Erbs et al. (1982):

$$
\begin{array}{ll}
f_{\mathrm{d}}=1.0-0.09 K_{\mathrm{a}} & \text { if } K_{\mathrm{a}} \leq 0.22 \\
f_{\mathrm{d}}=0.95-0.16 K_{\mathrm{a}}+4.38 K_{\mathrm{a}}^{2}-16.63 K_{\mathrm{a}}^{3}+12.33 K_{\mathrm{a}}^{4} & \text { if } 0.22<K_{\mathrm{a}} \leq 0.8 \\
f_{\mathrm{d}}=0.16 & \text { if } K_{\mathrm{a}}>0.8
\end{array}
$$

Then $S_{\mathrm{b} 0}$ and $S_{\mathrm{d} 0}$ at the top of the canopy are calculated from $f_{\mathrm{d}}$ using:

$$
\begin{aligned}
& S_{\mathrm{b} 0}=S_{0}\left(1-f_{\mathrm{d}}\right), \\
& S_{\mathrm{d} 0}=S_{0} f_{\mathrm{d}} .
\end{aligned}
$$


B.2 Radiation Attenuation Calculation

\section{B.2.1 Beam Component}

The extinction coefficient of the beam component, $K_{\mathrm{b}}$, for an ellipsoidal leaf distribution can be determined as (Campbell 1986; Campbell and Norman 1998):

$$
K_{\mathrm{b}}(\psi)=\frac{\left(x^{2}+\tan ^{2} \psi\right)^{0.5}}{x+1.774(x+1.182)^{-0.733}},
$$

where $\psi$ is the solar zenith angle, $x$ is the leaf angle distribution index. Note that Eq. 33 is the general expression for $K_{b}$, which includes the case of ellipsoidal leaf distribution $(x \neq 1)$ and spherical leaf angle distribution $(x=1)$. In this study, $x=1$ was assumed, which is reasonable for coniferous foliage (Schafer et al. 2003). The fraction $\tau_{\mathrm{b}}$ (or transmission coefficient) for the incoming beam from a given $\psi$ at different levels is given as:

$$
\tau_{\mathrm{b}}(\psi)=\exp \left[-K_{\mathrm{b}}(\psi) L_{\mathrm{t}}(z) \Pi\right],
$$

where $L_{\mathrm{t}}(z)$ is the cumulative PAD above level $z$, and $\Pi$ is the clumping factor due to the shading effect of other leaves (Stenberg 1998). The direct beam absorbed at level $z$ can be expressed as:

$$
S_{\mathrm{abs}, \mathrm{b}}(z)=S_{\mathrm{bo}} K_{\mathrm{b}} \alpha,
$$

where $\alpha$ is the absorptivity of the leaves for a given radiative waveband, which is $\approx 0.2$ for VIS, and $\approx 0.8$ for NIR (Campbell and Norman 1998).

\section{B.2.2 Diffuse Component}

To determine the extinction coefficient of diffuse radiation $\left(K_{d}\right)$ we approximated the fitted curve as a function of $L_{\mathrm{t}}(z)$ for $x=1$ after Campbell and Norman (1998) to give:

$$
\begin{array}{ll}
K_{\mathrm{d}}\left(L_{\mathrm{t}}\right)=-0.035 \log _{10}^{2} L_{\mathrm{t}}(z)-0.16 \log _{10} L_{\mathrm{t}}(z)+0.82 & \text { if } L_{\mathrm{t}}>0.01 \\
K_{\mathrm{d}}\left(L_{\mathrm{t}}\right)=1 & \text { if } L_{\mathrm{t}} \leq 0.01
\end{array} .
$$

The absorbed diffuse radiation $S_{a b s, d}(z)$ can be expressed as:

$$
S_{\mathrm{abs}, \mathrm{d}}(z)=S_{\mathrm{do}} \alpha^{0.5} K_{\mathrm{d}}\left(1-\rho_{\mathrm{cd}}\right) \tau_{\mathrm{d}},
$$

where $\rho_{\text {cd }}$ is the canopy reflection coefficient for diffuse component, and $\tau_{\mathrm{d}}$ is the transmission coefficient for the diffuse component and is given as:

$$
\tau_{\mathrm{d}}=\exp \left[-\alpha^{0.5} K_{\mathrm{d}}\left(L_{\mathrm{t}}\right) L_{\mathrm{t}}(z)\right] .
$$

\section{B.2.3 Scattered Component Inside the Canopy}

The total beam transmitted and scattered through the canopy to a given depth $L_{\mathrm{t}}(z)$ can be derived using the beam extinction coefficient (Eq. 31):

$$
\tau_{\mathrm{s}}(\psi)=\exp \left[-\alpha^{0.5} K_{\mathrm{be}}(\psi) L_{\mathrm{t}}(z) \Pi\right] .
$$

Therefore, the absorbed transmitted/scattered radiation at a given depth $L_{t}(z)$ can be expressed as:

$$
S_{\mathrm{abs}, \mathrm{s}}(z)=S_{\mathrm{b} 0}\left[\alpha^{0.5} K_{\mathrm{b}}\left(1-\rho_{\mathrm{cb}}\right) \tau_{\mathrm{s}}-K_{\mathrm{b}} \alpha \tau_{\mathrm{b}}\right]
$$




\section{B.3 Longwave Radiation Inside the Canopy Volume}

The isothermal net longwave radiation (Leuning et al. 1995) at the top of the canopy can be represented as:

$$
R_{\mathrm{L} 0}=\left(\varepsilon_{\mathrm{c}}-\varepsilon_{\mathrm{atm}}\right) \sigma T_{0}^{4},
$$

where $\varepsilon_{\mathrm{c}}(\approx 0.97)$ is the bulk canopy emissivity, $\sigma$ is the Stephan Boltzmann constant, $T_{0}$ is the air temperature at the canopy top, and $\varepsilon_{\mathrm{atm}}$ is the sky emissivity empirically given by (Brutsaert 1975):

$$
\varepsilon_{\mathrm{atm}}=0.642\left(e_{0} / T_{0}\right)^{1 / 7},
$$

where $e_{0}$ is water vapour pressure at the top of the canopy.

Once $R_{L 0}$ is obtained, the isothermal net longwave radiation through the canopy volume is estimated as (Leuning et al. 1995):

$$
R_{\mathrm{L}}(z)=R_{\mathrm{L} 0} K_{\mathrm{d}} \exp \left[-K_{\mathrm{d}} L_{\mathrm{t}}(z)\right] .
$$

\section{Appendix C: Forest Floor Boundary Conditions}

For the mean velocity, the no-slip boundary condition was imposed at the forest floor. For all higher-order flow statistics, a free-slip condition was assumed (i.e. $\partial(\cdot) / \partial z=0)$ ). As for $\mathrm{CO}_{2}$, the forest floor efflux $\left(F_{\mathrm{ff}}\right)$, derived by fitting chamber respiration measurements to soil temperature $\left(T_{\text {soil }}\right.$, in $\left.{ }^{\circ} \mathrm{C}\right)$ and soil moisture $\left(\theta\right.$, in $\left.\mathrm{m}^{3} \mathrm{~m}^{-3}\right)$, was used (Palmroth et al. 2005). The canonical form of the regression equation used to fit the chamber measurements is:

$$
F_{\text {ff }}\left(T_{\text {soil }}, \theta\right)=R_{\mathrm{b}} e^{a_{1} T_{\text {soil }}}\left[1-e^{(-b \theta+c)}\right]
$$

where $R_{b}$ is the base respiration, $a_{1}$ is the temperature sensitivity $\left(Q_{10}=\exp \left(10 a_{1}\right)\right)$ when soil moisture content is not limiting, and the constants $b$ and $c$ are soil moisture reduction parameters. The respiration parameters for 2001-2003 were given in Palmroth et al. (2005) and summarized by Juang et al. (2006). For 2004-2005, these parameters were $R_{\mathrm{b}}=0.817$, $a_{1}=0.103, b=-31.121, c=4.628$ for 2004 , and $R_{\mathrm{b}}=0.548, a_{1}=0.118, b=-29.511$, $c=3.301$ for 2005 .

As for the latent heat flux from the forest floor $\left(L_{\mathrm{v}} E_{\mathrm{ff}}\right)$, it is expressed as a function of the Bowen ratio $\beta_{\mathrm{o}}$, and given by

$$
L_{\mathrm{v}} E_{\mathrm{ff}}=\frac{1}{1+\beta_{\mathrm{o}}}\left(R_{\mathrm{n}, 0}-G\right)
$$

where $R_{\mathrm{n}, 0}$ is the forest floor net radiation estimated from the radiative attenuation model in Sect. 3.3 and Appendix B, and $G$ is the soil heat flux simply calculated from the measured soil temperature $T_{\text {soil }}$ at $0.1 \mathrm{~m}$ depth, air temperature just above the ground, and the mean thermal conductivity for soil $\left(\approx 0.5 \mathrm{~W} \mathrm{~m}^{-2} \mathrm{~K}^{-1}\right)$. Because the soil heat flux is small, heat storage in the upper soil layer is neglected. The value of $\beta_{\mathrm{o}}$ was computed from the surface gradients of air temperature $\left((\partial \bar{T} / \partial z)_{\mathrm{s}}\right.$ and humidity $\left.(\partial \bar{q} / \partial z)_{\mathrm{s}}\right)$ using

$$
\beta_{\mathrm{o}}=\left(\frac{C_{p}}{L_{v}}\right) \frac{(\partial \bar{T} / \partial z)_{\mathrm{s}}+\Gamma_{\mathrm{d}}}{(\partial \bar{q} / \partial z)_{\mathrm{s}}},
$$

where $\Gamma_{\mathrm{d}}$ is the dry adiabatic lapse rate. The surface gradients above were extrapolated from the measured mean water vapour concentration and temperature data. After $L_{\mathrm{v}} E_{\mathrm{ff}}$ is 
determined, the forest floor sensible heat flux $\left(H_{\mathrm{Sff}}\right)$ can be estimated as a residual using $H_{\text {Sff }}=R_{n, 0}-G-L_{\mathrm{v}} E_{\mathrm{ff}}$. Note that unlike the $\mathrm{CO}_{2}$ fluxes at the forest floor (specified using the chamber data), only extrapolated mean gradients from the profiles measurements were used to determine $\beta_{o}$ (i.e. the partitioning between sensible and latent heat fluxes). The radiative model was used to compute $R_{n, 0}$ in Eq. 45 .

\section{References}

Aber JD, Reich PB, Goulden ML (1996) Extrapolating leaf $\mathrm{CO}_{2}$ exchange to the canopy: a generalized model of forest photosynthesis compared with measurements by eddy correlation. Oecologia 106:257-265

Andre JC, Lacarrere P, Traore K (1981) Pressure effects on triple correlations in turbulent convective flows. Turbulent shear flows III. Springer-Verlag, Berlin, pp 243-252

Baldocchi D (1992) A Lagrangian random-walk model for simulating water vapour, $\mathrm{CO}_{2}$ and sensible heat flux densities and scalar profiles over and within a soybean canopy. Boundary-Layer Meteorol 61:113-144

Baldocchi D, Meyers T (1998) On using eco-physiological, micrometeorological and biogeochemical theory to evaluate carbon dioxide, water vapour and trace gas fluxes over vegetation: a perspetive. Agric Forest Meteorol 90:1-25

Baldocchi DJ, Vogel C, Hall B (1997) Seasonal variation of carbon dioxide exchange rates above and below a boreal jack pine forest. Agric Forest Meteorol 83:147-170

Baldocchi DD, Falge E, Gu L, Olson R, Hollinger D, Running S, Anthoni P, Bernhofer C, Davis K, Fuentes J, Goldstein A, Katul G, Law B, Lee X, Malhi Y, Meyers T, Munger JW, Oechel W, Pilegaard K, Schmid HP, Valentini R, Verma S, Vesala T, Wilson K, Wofsy S (2001) FLUXNET: a new tool to study the temporal and spatial variability of ecosystem-scale carbon dioxide, water vapour and energy flux densities. Bull Amer Meteorol Soc 82:2415-2435

Ball JT, Woodrow IE, Berry JA (1987) A model predicting stomatal conductance and its contribution to the control of photosynthesis under different environmental conditions. In: Biggins J (ed) Progress in photosynthesis research. Martinus Nijhoff, Amsterdam Netherlands pp 221-224

Brutsaert W (1975) On a derivable formula for long-wave radiation from clear skies. Water Resour Res 11:742744

Butnor JR, Johnsen KH (2004) Calibrating soil respiration measures with a dynamic flux apparatus using artificial soil media of varying porosity. Eur J Soil Sci 55:639-647

Butnor JR, Johnsen KH, Oren R (2003) Reduction of forest floor respiration by fertilization on both carbon dioxide-enriched and reference 17-year-old loblolly pine stands. Global Change Biol 9:849-861

Campbell GS (1986) Extinction coefficients for radiation in plant canopies calculated using an ellipsoidal inclination angle distribution. Agric Forest Meteorol 36:317-321

Campbell GS, Norman JM (1998) An introduction to environmental biophysics. Springer-Verlag, New York $307 \mathrm{pp}$

Collatz GJ, Ball JT, Crivet C, Berry JA (1991) Physiological and environmental regulation of stomatal conductance, photosynthesis and transpiration: a model that Includes a laminar boundary layer. Agric Forest Meteorol 54:107-136

De Pury DGG, Farquhar GD (1997) Simple scaling of photosynthesis from leaves to canopies without the errors of big-leaf models. Plant Cell Environ 20:537-557

Detto M, Katul GG (2007) Simplified expressions for adjusting higher-order turbulent statistics obtained from open path gas analyzers. Boundary-Layer Meteorol 122:205-216

Ellsworth DS (1999) $\mathrm{CO}_{2}$ enrichment in a maturing pine forest: are $\mathrm{CO}_{2}$ exchange and water status in the canopy affected. Plant Cell Environ 22:461-472

Ellsworth DS (2000) Seasonal $\mathrm{CO}_{2}$ assimilation and stomatal limitations in a Pinus taeda canopy. Tree Physiol 20:435-445

Erbs DG, Klein SA, Duffie JA (1982) Estimation of the diffuse radiation fraction for hourly, daily and monthly average global radiation. Sol Energy 28:293

Farquhar GD, Von Caemmerer S, Berry JA (1980) A biochemical model of photosynthetic $\mathrm{CO}_{2}$ assimilation in leaves of $\mathrm{C}_{3}$ species. Planta 149:79-90

Goudriaan J, van Laar HH (1994) Modelling potential crop growth processes. Kluwer Academic Publishers, Dordrecht $256 \mathrm{pp}$

Gu L, Shugart HH, Fuentes JD, Black TA, Shewchuk SR (1999) Micrometeorology, biophysical exchanges and NEE decomposition in a two-story boreal forest-development and test of an intergrated model. Agric Forest Meteorol 94:123-148 
Jackson PS (1981) On the displacement height in the logarithmic velocity profile. J Fluid Mech 111:15-25

Juang J-Y, Katul GG, Siqueira MBS, Stoy PC, Palmroth S, McCarthy HR, Kim H, Oren R (2006) Modeling nighttime ecosystem respiration from measured $\mathrm{CO}_{2}$ concentration and air temperature profiles using inverse methods. J Geophys Res-Atmos 111:D08S05

Juang J-Y, Katul GG, Porporato A, Stoy PC, Siqueira M, Detto M, Kim H-S, Oren R (2007a) Eco-hydrological controls on summertime convective rainfall triggers. Global Change Biol 13(4):887-896

Juang J-Y, Porporato A, Stoy PC, Siqueira MBS, Oishi CA, Detto M, Kim H-S, Katul GG (2007b) Hydrologic and atmospheric controls on initiation of convective precipitation events. Water Resour Res 43:W03421

Kaimal JC, Finnigan JJ (1994) Atmospheric boundary layer flows: their structure and measurements. Oxford University Press, $289 \mathrm{pp}$

Katul GG, Albertson JD (1998) An investigation of higher-order closure model for a forested canopy. Boundary-Layer Meteorol 89:47-74

Katul GG, Chang WH (1999) Principal length scales in second-order closure models for canopy turbulence. J Appl Meteorol 38:1631-1643

Katul GG, Leuning R, Oren R (2003) Relationship between plant hydraulic and biochemical properties derived from a steady-state coupled water and carbon transport model: Plant Cell Environ 26:339-350

Katul GG, Mahrt L, Poggi D, Sanz C (2004) One and two equation models for canopy turbulence. BoundaryLayer Meteorol 113:91-109

Kirschbaum MUF, Küppers M, Schneider HGC, Noe S (1998) Modelling photosynthesis in fluctuating light with inclusion of stomatal conductance, biochemical activation and pools of key photosynthetic intermediates. Planta 204:16-26

Lai C-T, Katul GG, Oren R, Ellsworth D, Schafer K (2000a) Modeling $\mathrm{CO}_{2}$ and water vapour turbulent flux distributions within a forest canopy. J Geophys Res Atmos 105(D21):26333-26351

Lai C-T, Katul GG, Ellsworth D, Oren R (2000b) Modelling vegetation-atmosphere $\mathrm{CO}_{2}$ exchange by a coupled Eulerian-Langrangian approach. Boundary-Layer Meteorol 95:91-122

Lai C-T, Katul GG, Butnor JR, Siqueira M, Ellsworth DS, Maier C, Johnsen KH, McKeand S, Oren R (2002a) Modeling the limits on the response of net carbon exchange to fertilization in a southeastern pine forest. Plant Cell Environ 25:1095-1119

Lai C-T, Katul GG, Butnor J, Ellsworth D, Oren R (2002b) Modelling night-time ecosystem respiration by a constrained source optimization method. Global Change Biol 8:124-141

Leuning R, Kelliher FM, De Pury DGG, Schulze E-D (1995) Leaf nitrogen, photosynthesis, conductance and transpiration: scaling from leaves to canopies. Plant Cell Environ 18:1183-1200

Leuning R (2000) Estimation of scalar sources/sink distributions in plant canopies using Lagrangian dispersion analysis: corrections for atmospheric stability and comparison with a multilayer canopy model. Boundary-Layer Meteorol 96:293-314

Liu J, Black TA, Novak MD (1996) E-epsilon modeling of turbulent air flow downwind of a model forest edge. Boundary-Layer Meteorol 77:21-44

Luo Y, Medlyn B, Hui D, Ellsworth DS, Reynolds JF, Katul G (2001) Gross primary productivity in the Duke forest: modeling synthesis of the free-air $\mathrm{CO}_{2}$ enrichment experiment and eddy-covariance measurements. Ecol Appl 11:239-252

Malhi Y, Nobre AD, Grace J, Kruijt B, Pereira MGP, Culf A, Scott S (1998) Carbon dioxide transfer over a Central Amazonian rain forest. J Geophys Res Atmos 103:31593-31612

Massman WJ, Weil JC (1999) An analytical one-dimensional second-order closure model of turbulence statistics and the Lagrangian time scale within and above plant canopies of arbitrary structure. Boundary-Layer Meteorol 91:81-107

McCarthy HR, Oren R, Finzi AC, Johnsen KH (2006a) Canopy leaf area constrains $\left[\mathrm{CO}_{2}\right]$-induced enhancement of productivity and partitioning among aboveground carbon pools. Proc Natl Acad Sci USA 103:19356-19361

McCarthy HR, Oren R, Kim H-S, Johnsen KH, Maier C, Pritchard SG, Davis MA (2006b) Interaction of ice storms and management practices on current carbon sequestration in forests with potential mitigation under future $\mathrm{CO}_{2}$ atmosphere. J Geophys Res Atmos 111:D15103

McCarthy HR, Oren R, Finzi AC, Ellsworth DS, Kim H-S, Johnsen KH, Millar B (2007) Temporal dynamics and spatial variability in the enhancement of canopy leaf area under elevated atmospheric $\mathrm{CO}_{2}$. Global Change Biol 13:2479-2497

Mellor G (1973) Analytic prediction of the properties of stratified planetary boundary layer. J Atmos Sci 30:1061-1069

Meyers T, Paw UKT (1986) Testing of a higher-order closure model for modeling airflow within and above plant canopies. Boundary-Layer Meteorol 37:297-311

Meyers T, Paw UKT (1987) Modeling the plant canopy micrometeorology with higher-order closure principles. Agric Forest Meteorol 41:143-163 
Naumburg E, Ellsworth DS (2000) Photosynthetic sunfleck utilization potential of understory saplings growing under elevated $\mathrm{CO}_{2}$ in FACE. Oecologia 122:163-174

Naumburg E, Ellsworth DS, Katul GG (2001) Modeling daily understory photosynthesis of species with differing photosynthetic light dynamics in ambient and elevated $\mathrm{CO}_{2}$. Oecologia 126:487-499

Nikolov NT, Massman WJ, Schoettle AW (1995) Coupling biochemical and biophysical processes at the leaf level: an equilibrium photosynthesis model for leaves of $\mathrm{C}_{3}$ plants. Ecol Model 80:205-235

Oren R, Ewers B, Todd P, Phillips N, Katul GG (1998) Water balance delineates the soil layer in which moisture affects canopy conductance. Ecol Appl 8:990-1002

Palmroth S, Maier CA, McCarthy HR, Oishi AC, Kim H-S, Johnsen KH, Katul GG, Oren R (2005) Contrasting responses to drought of forest floor $\mathrm{CO}_{2}$ efflux in a loblolly pine plantation and a nearby oak-hickory forest. Global Change Biol 11:1-14

Pataki DE, Oren R (2003) Species differences in stomatal control of water loss at the canopy scale in a mature bottomland deciduous forest. Adv Water Resour 26(12):1267-1278

Pataki DE, Oren R, Tissue D (1998) Elevated carbon dioxide does not affect average canopy stomatal conductance of Pinus taeda L. Oecologia 127:549-559

Penman HL (1948) Natural evaporation from open water, bare soil and grass. Proc Roy Soc London Ser A 193:120-146

Poggi D, Katul GG, Albertson JD (2004) Momentum transfer and turbulent kinetic energy budgets within a dense model canopy. Boundary-Layer Meteorol 111:589-614

Raupach MR (1988) Canopy transport processes. In: Steffen WL, Denmead OT (eds) Flow and transport in the natural environment: advances and applications. Springer-Verlag, New York, pp 95-127

Raupach MR (1989) A practical Lagrangian method for relating scalar concentrations to source distributions in vegetation canopies. Quart J Roy Meteorol Soc 115:609-632

Schafer KVR, Oren R, Ellsworth DS, Lai C-T, Herrick JD, Finzi AC, Richter DD, Katul GG (2003) Exposure to an enriched $\mathrm{CO}_{2}$ atmosphere alters carbon assimilation and allocation in a pine forest ecosystem. Global Change Biol 9:1378-1400

Shaw RH, Hartog GD, Neumann HH (1988) Influence of foliar density and thermal stability on profiles of Reynolds stress and turbulence intensity in a deciduous forest. Boundary-Layer Meteorol 45(4):391-409

Simon E, Meixner FX, Ganzeveld L, Kesselmeier J (2005a) Coupled carbon-water exchange of the Amazon rain forest, I. Model description, parameterization and sensitivity analysis. Biogeosciences 2:231-253

Simon E, Meixner FX, Rummel U, Ganzeveld L, Ammann C, Kesselmeier J (2005b) Coupled carbon-water exchange of the Amazon rain forest, II. Comparison of predicted and observed seasonal exchange of energy, $\mathrm{CO}_{2}$, isoprene and ozone at a remote site in Rondônia. Biogeosciences 2:255-275

Siqueira M, Katul G (2002) Estimating heat sources and fluxes in thermally stratified canopy flows using higher-order closure models. Boundary-Layer Meteorol 103:125-142

Siqueira M, Kutal GG, Lai C-T (2002) Quantifying net ecosystem exchange by multilevel ecophysiological and turbulent transport models. Adv Water Resour 25:1357-1366

Spitters CJT, Toussaint HAJM, Goudriaan J (1986) Separating the diffuse and direct component of global radiation and its implications for modelling canopy photosynthesis. Part I. Components of incoming radiation. Agric Forest Meteorol 38:225-237

Spitters CJT (1986) Separating the diffuse and direct component of global radiation and its implications for modelling canopy photosynthesis. Part II. Calculation of canopy photosynthesis. Agric Forest Meteorol 38:238-241

Stenberg P (1998) Implications of shoot structure on the rate of photosynthesis at different levels in a coniferous canopy using a model incorporating grouping and penumbra. Funct Ecol. 12: 82-91

Stoy P, Katul GG, Siqueira MBS, Juang J-Y, McCarthy HR, Kim H-S, Oishi C, Oren R (2005) Variability in net ecosystem exchange from hourly to inter-annual time scales at adjacent pine and hardwood forests: a wavelet analysis. Tree Physiol 25:887-902

Stull RB (1988) An introduction to boundary layer meteorology. Kluwer Academic Publishers Group, Dordrecht, $666 \mathrm{pp}$

Su H-B, Paw UKT, Shaw RH (1996) Development of a coupled leaf and canopy model for the simulation of plant-atmosphere interaction. J Appl Meteorol 35:733-748

Thom AS (1971) Momentum absorption by vegetation. Quart J Roy Meteorol Soc 97: 414-428

Wang YP, Leuning R (1998) A two-leaf model for canopy conductance, photosynthesis and partitioning of available energy I: Model description and comparison with a multi-layered model. Agric Forest Meteorol 91:89-111

Webb EK, Pearman GI, Leuning R (1980) Correction of flux measurements for density effects due to heat and water vapour transfer. Quart J Roy Meteorol Soc 106: 85-100

Weiss A, Norman JM (1985) Partitioning solar radiation into direct and diffuse, visible and near-infrared components. Agric Forest Meteorol 34:205-213 
Williams M, Rastetter EB, Fernades DN, Goulden MLC, Wofsy S, Shaver GR, Meillo JM, Munger JW, Fan SM, Nadelhoffer KJ (1996) Modeling the soil-plant-atmosphere continuum in a Quercus-Acerstand at Harvard forest: the regulation of stomatal conductance by light, nitrogen and soil/plant hydraulic properties. Plant Cell Environ 19:911-927

Williams M, Malhi Y, Nobre AD, Rastetter EB, Grace J, Pereira MGP (1998) Seasonal variation in net carbon exchange and evapotranspiration in a Brazilian rain forest: a modelling analysis. Plant Cell Environ 21:953-968

Wilson JD (1989) Turbulent transport within the plant canopy. In: Blackman TA et al (eds) Estimation of areal evapotranspiration. IAHS Pub., Gentbrugge, Belgium, pp 43-80

Wilson NR, Shaw RH (1977) A higher order closure model for canopy flow. J Appl Meteorol 16:1198-1205 